\title{
Astroglial asthenia and loss of function, rather than reactivity, contribute to the ageing of the brain
}

DOI:

10.1007/s00424-020-02465-3

\section{Document Version}

Accepted author manuscript

Link to publication record in Manchester Research Explorer

\section{Citation for published version (APA):}

Verkhratsky, A., Augusto-oliveira, M., Pivorinas, A., Popov, A., Brazhe, A., \& Semyanov, A. (2020). Astroglial asthenia and loss of function, rather than reactivity, contribute to the ageing of the brain. Pflügers Archiv European Journal of Physiology. https://doi.org/10.1007/s00424-020-02465-3

\section{Published in:}

Pflügers Archiv European Journal of Physiology

\section{Citing this paper}

Please note that where the full-text provided on Manchester Research Explorer is the Author Accepted Manuscript or Proof version this may differ from the final Published version. If citing, it is advised that you check and use the publisher's definitive version.

\section{General rights}

Copyright and moral rights for the publications made accessible in the Research Explorer are retained by the authors and/or other copyright owners and it is a condition of accessing publications that users recognise and abide by the legal requirements associated with these rights.

\section{Takedown policy}

If you believe that this document breaches copyright please refer to the University of Manchester's Takedown Procedures [http://man.ac.uk/04Y6Bo] or contact uml.scholarlycommunications@manchester.ac.uk providing relevant details, so we can investigate your claim.

\section{OPEN ACCESS}




\title{
Astroglial asthenia and loss of function, rather than reactivity, contribute to the ageing of the brain
}

\author{
Alexei Verkhratsky ${ }^{1,2}$ Marcus Augusto-Oliveira ${ }^{3}$, Augustas Pivoriūnas ${ }^{4}$ Alexander \\ Popov $^{5}$, Alexey Brazhe ${ }^{5,6} \&$ Alexey Semyanov ${ }^{5,7}$ \\ ${ }^{1}$ Faculty of Biology, Medicine and Health, The University of Manchester, Manchester, \\ M13 9PT, UK; ${ }^{2}$ Achucarro Center for Neuroscience, IKERBASQUE, Basque \\ Foundation for Science, 48011 Bilbao, Spain \& Department of Neurosciences, \\ University of the Basque Country UPV/EHU and CIBERNED, Leioa, Spain; \\ ${ }^{3}$ Laboratório de Farmacologia Molecular, Instituto de Ciências Biológicas, \\ Universidade Federal do Pará, 66075-110 Belém, Brasil; ${ }^{4}$ Department of Stem Cell \\ Biology, State Research Institute Centre for Innovative Medicine, LT-01102, Vilnius, \\ Lithuania; ${ }^{5}$ Shemyakin-Ovchinnikov Institute of Bioorganic Chemistry, Russian \\ Academy of Sciences, Miklukho-Maklaya street 16/10, Moscow, 117997, Russia; \\ ${ }^{6}$ Moscow State University, Moscow, Russia; ${ }^{7}$ Sechenov First Moscow State Medical \\ University, Moscow, Russia
}

Send all correspondence to:

Prof. Alexei Verkhratsky

Faculty of Biology, Medicine and Health

University of Manchester

Manchester, M13 9PT, UK

Alexej.Verkhratsky@manchester.ac.uk

or

Alexey Semyanov

Shemyakin-Ovchinnikov Institute of Bioorganic Chemistry,

Russian Academy of Sciences,

Miklukho-Maklaya street 16/10,

Moscow, 117997, Russia

semyanov@neuro.nnov.ru 


\begin{abstract}
Astroglia represents a class of heterogeneous, in form and function, cells known as astrocytes, which provide for homoeostasis and defence of the central nervous system (CNS). Ageing is associated with morphological and functional remodelling of astrocytes with a prevalence of morphological atrophy and loss of function. In particular ageing is associated with (i) decrease in astroglial synaptic coverage; (ii) deficits in glutamate and potassium clearance; (iii) reduced astroglial synthesis of synaptogenic factors such as cholesterol; (iv) decrease in aquaporin 4 channels in astroglial endfeet with subsequent decline in the glymphatic clearance; (v) decrease in astroglial metabolic support through the lactate shuttle; (vi) decreased adult neurogenesis resulting from diminished proliferative capacity of radial stem astrocytes; (vii) decline in the astroglial-vascular coupling and deficient blood-brain barrier and (viii) decrease in astroglial ability to mount reactive astrogliosis. Decrease in reactive capabilities of astroglia is associated with increase in age-dependent neurodegenerative diseases. Astroglial morphology and function can be influenced and improved by lifestyle interventions such as intellectual engagement, social interactions physical exercise, caloric restriction, and healthy diet. These modifications of lifestyle are paramount for cognitive longevity.
\end{abstract}

Key words: Ageing; astrocyte; astroglial perisynaptic cradle; astroglial function; synaptic transmission; reactive astrogliosis; neuroplasticity 


\section{The resilient ageing brain}

The age-dependent decrease in brain function is often portrayed as the main outcome of ageing which stems from an intrinsic propensity of the nervous tissue to degenerate; the view on progressive loss of neurones with age is a commonplace while looming "pandemic" of dementia seems to erect impenetrable barrier for keeping the quality of life of the ageing humanity. Nonetheless, when compared with other organs and systems the brain ages most graciously; which has been documented already on one of the very first epidemiologic investigation of nearly 900 elderly (more than 80 years old), including 74 centenarians. This investigation, published in Cambridge in 1889, arrived to the following conclusion: "Indeed, the brain in many held out as well or better than other organs - which may be regarded one of the bright rays, if not the brightest, in the centenarian landscape."1

Looking into brain ageing from an unbiased perspective one need to consent with the obvious fact that many peripheral systems start functional decline much earlier than the cognitive abilities begun to suffer: intelligence at 40 is usually blossoming and continues to evolve, providing that an individual maintained healthy lifestyle, whereas at the same age man rarely successfully compete in physical abilities with youngsters. The long-lasting postnatal development of cognitive capacity is defined by the nature of the nervous tissue, and neuroplasticity which needs an environmental input - i.e. learning - to shape and remodel the cellular circuits and neuronal ensembles. Brain plasticity is operational throughout the lifespan; and many mechanisms supporting remodelling of brain connectivity last well into the adulthood. Excessive plasticity of the young brain creates an environment in which the brain is constantly changing and readjusting to the environmental conditions. This requires energy consumption and slows the decision-making. The plasticity of the brain decreases with age when brain wiring and synaptic strength is refined by experience. Hence, in the adult brain, plasticity is gradually replaced by network stability, which allows much faster performance in familiar settings at the expense of new skills acquisition. Thus, brain ageing can be viewed as a change of balance between plasticity and stability. Neuroglia play an important role in regulating both plasticity and stability of synapses and neurones, thus guiding and modulating the ageing of the nervous system.

Neuronal activity is highly energy demanding and hence throughout life the nervous tissue exists under continuous pressure of high production of reactive oxygen species. High protein synthesis requires effective system for clearance of by-products and proteinaceous waste, while ionic fluxes associated with neuronal excitability need a robust system regulating ion composition of the interstitial fluid. Finally, the brain is in need of defensive systems that may protect it against systemic influences or ongoing microtraumas. All in all, proper brain function presents a substantial logistical challenge that is met by specialised class of homoeostatic cells known as neuroglia.

The distinction between physiological brain ageing (with largely preserved cognitive capacity) and pathological brain ageing (which is associated with neurodegeneration and evolves towards dementia) is defined by the cognitive reserve. The cognitive

\footnotetext{
${ }^{1}$ George Murray Humphry, 1889, The Old Age. The results of information received respecting nearly nine hundred persons who had attained the age of eighty years, including seventy-four centenarians. MacMillan \& Bowes, Cambridge, p. 48
} 
reserve is an individual property of every organism; it reflects the lifelong interaction of genetic factors with environment and accumulated pathological damages. The cognitive reserve to a very large extent defines the cognitive outcome for different individuals and arguably defines the progression of neurodegenerative diseases [186; 226]. Conceptually, the cognitive reserve is a function of (i) neuronal reserve and (ii) neuronal compensation. The neuronal reserve reflects the functional structure of the brain as a result of life-long learning while neuronal compensation is determined by the capacity of the nervous tissue and the brain as an organ to defend itself, to limit the damage and to regenerate. Neuroglia largely defines neuronal compensation, and therefore ageing of neuroglia is fundamental for cognitive status of the aged brain. Furthermore, age-dependent decline in glial function may be the decisive factor in determining the resistance of the nervous tissue to neurodegeneration: failure of neuroglia facilitates the transition from physiological to pathological ageing [202].

\section{Neuroglia defines cognitive reserve of the ageing brain}

Neuroglia of the CNS are represented by three major cell classes (i) the homoeostatic astroglia; (ii) the myelinating oligodendroglia and their precursors also known as NG2 glia and (iii) the microglia $[87 ; 201]$. Neuroglial cells contribute to cognition though multiple mechanisms. The oligodendrocytes are the central cellular element of the brain connectome though myelination of white matter tracts and grey matter axons. Myelination in the human brain spans through adulthood, probably into $4^{\text {th }}$ or even $5^{\text {th }}$ decade of life $[9 ; 213]$; the myelination of the grey matter axons can be operational even longer. The brain is populated by NG-2 glia, which arguably maintain myelination (through differentiation into oligodendrocytes) in advanced ages [26]. Microglial cells not only provide an innate immune defence for the CNS but also modulate synaptic transmission and eliminate redundant or non-functional synapses thus assisting in tailoring neuronal ensembles [86]. Finally, astrocytes are responsible for homoeostatic control of CNS on all levels of organisation [204] as well as for defence of nervous tissue through evolutionary conserved programme or reactive astrogliosis [143]. Astrocytes are indispensable elements of synaptic connectivity: astrocytic processes predominantly enwrap dendritic spines, in less degree presynaptic boutons and in the least degree dendritic shafts [55]. Astrocytic processes are classified into organelle-containing branches and branchlets, terminal organelle-free leaflets and blood-vessel-contacting endfeet [55]. Astroglial perisynaptic processes are predominantly leaflets [55] that cover $\sim 60 \%$ of synapses in the brain and form astroglial synaptic cradle, which contributes to synaptogenesis, synaptic maturation, synaptic maintenance, and synaptic extinction [6;203].

Ageing affects all types of glia. The white matter suffers the most even in the physiological ageing: reduction in white matter volume in old age reaches up to $\sim 11 \%$, while grey matter shrinks by only 3\% [65]. This paralleled with decrease of numbers or atrophy of oligodendrocytes and loss of NG2 glia associated with the decline in its differentiating capacity $[8 ; 50 ; 149 ; 161 ; 199]$. Similarly, microglial cells undergo substantial changes in ageing which essentially decrease their protective potential. In humans, ageing is associated with dystrophy and degeneration of microglia; aged microglial cells have shorter and less branched processes, which often demonstrate fragmentation; these dystrophic microglia have reduced activation capacity $[38 ; 187$; $189 ; 190]$. Arguably this deterioration of microglia lessens inflammatory capabilities of the old brain, reduces neuroprotection and facilitates neurodegeneration [188]. 
Astroglial function also diminishes with ageing as shall be detailed below. All in all, age-dependent decrease in neuroglial support impacts on cognitive reserve thus defining the speed of cognitive decline.

\section{Transcriptome of ageing astrocytes}

Recent decade has witnessed a surge in transcriptomic analysis of the brain; these started with microarray-based technologies, which were succeeded with RNAsequencing and single-cell RNA sequencing approaches. Studies of astroglial transcriptomic profiles in both healthy and diseased brain tissues confirmed their remarkable regional heterogeneity and regional specialisation $[74 ; 80 ; 138 ; 224]$. Analysis of gene expression in ageing revealed that changes in glial transcriptome are much more substantial that in neurones, once more highlighting the fundamental role played by neuroglia in the process of brain ageing. Transcriptome profiling of postmortem tissue obtained from $16-102$ years old humans found prominent and complex changes in gene expression in oligodendrocytes and astrocytes; whereas neuronal patterns remained unchanged [184]. Aged mouse cortical astrocytes showed an increase in genes linked to an immune response with a decrease in expression of glial fibrillary acidic protein (GFAP) and genes related to neuroprotection and neuronal support [139]. Another study of the mouse brain (motor and visual cortex, hypothalamus and cerebellum) revealed age-dependent up-regulation of astroglial genes responsible for synapse elimination; these changes were the most prominent in hippocampus and cerebellum [16]. The singe-cell RNA sequencing of $\sim 50000$ singlecell transcriptomes from young (3-4 months) and old (21-23 months) mice demonstrated substantial regional heterogeneity of age-dependent changes indicating that ageing of neurones and glia may develop through distinct molecular pathways [223]. The transcriptomic data are now scrutinised by proteomic studies: the largescale proteomic analysis of more than 2000 healthy and diseased human brain samples found that the group of proteins associated with neuroglia are the most affected in Alzheimer's disease (AD). Many of these proteins are associated with antiinflammatory and neuroprotective cascades [81]. Our knowledge of genetic changes and variations with ageing is in statu nascendi; of course, linking transcriptomics and proteomics data to functional outcomes and physiological processes is a daunting task and yet information accumulated so far points towards substantial adaptive changes in astrocytic gene expression in the process of brain ageing.

\section{Ageing astrocytes are not bona fide reactive}

\section{Pathophysiology of astrocytes: from degeneration and atrophy to reactive astrogliosis}

Pathological changes in astroglia can generally be classified into several distinct groups (Fig. 1). These groups are: (i) Reactive astrogliosis; (ii) Astroglial atrophy with loss of function; (iii) Pathological remodelling and (iv) Astroglial degeneration and death.

Reactive astrogliosis is one of the most researched and universally accepted classes of astroglial pathology. The concept of astrogliosis as one of the most frequent response of astrocyte to brain lesions has been developed in 1920s [40; 146]. Reactive astrogliosis is the evolutionary conserved response of astroglia to pathological stimuli (of whatever nature, from acute trauma and infection to chronic neurodegeneration or 
epilepsy) in which astrocytes undergo activation of molecular programs that instigate biochemical, morphological and physiological remodelling of these cells with an ultimate goal of protection of the nervous tissue $[143 ; 181 ; 182 ; 210]$. Reactive astrogliosis is, by definition, secondary to the lesion; initiation of reactive reprogramming by pathological insults results in emergence of multiple diseasespecific reactive phenotypes. Recently proposed ideas of binary division of reactive astrocytes into "neuroprotective" or "neurotoxic" (so called A1/A2 dichotomy), originated from over-interpretation of limited data sets, have been misleading and detrimental to the field; numerous investigations had demonstrated remarkable diversity of reactive astrocytic phenotypes $[2 ; 61 ; 69 ; 218]$. Contrary to common neurological believes of deleterious reactive astrocytes, astrogliosis is fundamentally neuroprotective, and direct astroglial toxicity (i.e. secretion of neurotoxic agents) has not been unequivocally demonstrated hitherto. The detrimental effects of chronic astrogliosis $[143 ; 144]$ are most likely associated with loss of astroglial homoeostatic and protective function. In summary, the reactive astrogliosis is graded, contextdependent and reversible.

Astroglial atrophy as general pathological entity begun to receive attention in recent decade; morphological atrophy of astrocytes often associated with loss of homoeostatic functions contribute to numerous diseases, including neuropsychiatric diseases, addictive disorders, epilepsy, acute neurodegeneration such as WernickeCorsakoff syndrome and neurodegenerative diseases, including Alzheimer disease $[51 ; 180 ; 206]$. Astroglial atrophy may be primary, when it drives pathology, and secondary, when atrophic changes arise from injury or astrodegeneration; sometimes shrinkage of astroglial peripheral processes may even accompany astrogliosis [151]. Some astroglial sub-populations show higher degree of atrophy: for example, severe neurodegeneration in human brain is associated with almost complete loss of processes of interlaminar astrocytes [32]. Astroglial morphological atrophy underlies reduced synaptic coverage and diminished synaptic support, which in turn may contribute to the cognitive decline [205]. Since astrocytic $\mathrm{Ca}^{2+}$ activity strongly depends on astrocyte morphology, $\mathrm{Ca}^{2+}$ signalling is reduced in these cells $[151 ; 221]$. Because astrocytic $\mathrm{Ca}^{2+}$ activity is linked to number of physiological properties of this cells including synaptic coverage [196], such reduction in $\mathrm{Ca}^{2+}$ signalling may further exacerbate astrocytic atrophy.

Astrodegeneration is the most extreme form of astrogliopatholgy; it may appear in a form of clasmatodendrosis or astroglial death, apoptotic or necrotic. Clasmatodendrosis (from Greek (from Greek "k $k \alpha \alpha \sigma \mu \alpha$ ", fragment, " $\delta \varepsilon \dot{v} \delta \rho o v "$, tree, " $\omega \sigma \iota \varsigma "$, process) represents a specific form of astrodegeneration. Initially characterised by Alzheimer and Cajal (see [146]) it was for a long time neglected, although several recent studies described clasmatodendrosis in ischaemia, infectious encephalopathies, stroke, psychiatric diseases and ageing $[71 ; 172 ; 195]$. Clasmatodendrosis is characterised by fragmentation of astroglial processes, disappearance of distal fine processes, together with swelling and vacuolation of the cell body. Finally lesions to the brain can cause astroglial death by necrosis or apoptosis.

Morphology of astrocytes in the old brain 
Studies of GFAP expression in the old brain almost universally revealed an increase in its global expression at both mRNA and protein levels (Table 1), while other archetypal astroglial markers such as protein S100B or glutamine synthetase (GS) remain unchanged. It is generally agreed that physiological ageing is not associated with any substantial decrease in astroglial cell numbers across CNS regions, although the data are not uniform (Table 2). Similarly, the data on the morphological appearance of astrocytes in the old brains are contradictory: both increase and decrease in size and complexity of astrocytes have been reported (Table 2). It has to be specifically noted that absolute majority of morphological studies have been performed on astrocytes immunostained for GFAP. The GFAP as a morphological marker is not ideal; it is labelling the cytoskeleton and completely misses peripheral processes that account for the largest part of astrocyte surface [157]. Moreover, an increase in GFAP-positive profile does not necessarily reports the true astrocyte hypertrophy; the territorial domains of reactive astrocytes remain largely unchanged [219]. Furthermore, an increase in GFAP expression and a cytoskeletal hypertrophy, although being widely recognised as a marker of astrogliosis, is not always linked to astroglial reactivity. For instance, expression of GFAP undergoes circadian fluctuations in the supraoptical nerve $[11 ; 75]$. Moreover, GFAP and astroglial morphology respond to environmental stress: both physical exercise and exposure to enriched environment is known to substantially increase GFAP-positive astroglial profiles in various regions of the brain $[43 ; 164 ; 175]$. Another important parameter that has to be carefully considered is the choice of age groups. Maximal increase in GFAP expression, size and complexity of astrocytes occurs in postnatal development, during the first year of life of rodents ([14; 90], see also Fig. 2). A substantial increase in GFAP expression as well as in size and complexity of astroglial profiles has been observed during first year of life of African giant rats [136]; similar remarkable increase in astrocytic size and complexity characterised the transition from juvenile to adolescent monkeys [158]. In consequence, comparing old and young animals may reveal a dramatic increase in size of old astrocytes; whereas comparing the same old astrocytes with cells from adult animals may not reveal a major difference.

There are scarcely a handful of studies analysing astrocytes labelled with markers other than GFAP. The Golgi staining of old astrocytes (which in skilful hands produce detailed morphological images) did not reveal any age-dependent changes [28]. Probing of astrocytes from mice of different ages (3, 9, 18, 24 months old) with antibodies against GFAP, glutamate synthetase and protein S100B showed rather complex and region-dependent changes (Fig. 3 and [166]). The GFAP-positive profiles were increased in CA1 region and in dentate gyrus of old hippocampus but substantially decreased in the entorhinal cortex (EC); GS-positive astrocytes were smaller in old hippocampus but larger in old EC, and finally S100B-positive profiles from old animals demonstrated an increase in EC, much smaller increase in DG and no changes in CA1. In summary, it seems that different astroglial sub-population may undergo distinct changes in ageing.

Finally, the morphology of astrocytes in brain slices from mice of different ages (3, 9 and 24 months) was visualised using intercellular perfusion with low molecular weight fluorescent probe Alexa Fluor 594 [152]. This fluorescent probe diffuses through the cytosol and penetrates in the most distant parts of the cell labelling even tiny perisynaptic processes. Two-photon imaging with subsequent 3D reconstruction of Alexa Fluor 594 labelled astrocytes revealed substantial increase in the size and 
complexity of astrocytes in development from youth to adulthood; and significant decrease in size and complexity of astrocytes in old animals (Fig. 2). Furthermore, using Alexa Fluor 594 fluorescence in combination with two-photon microscopy, we were able to characterise the status of peripheral and perisynaptic astroglial processes. To this end we measure the volume fraction of peripheral processes as the fluorescence ratio of unresolved processes area to the astrocyte soma [151; 153]. This approach presumes that fluorescence measured from the soma reflects $100 \%$ of astrocyte space occupancy, whereas the fluorescence of unresolved area is proportional to the volume fraction of optically irresolvable astrocyte processes in any given area [114]. It turned out that the volume fraction occupied by peripheral processes diminishes with age, thus indicating decreased astroglial synaptic coverage in the old brain [152]. Astroglial peripheral processes are one of the main contributors to the neuropil [194], and their shrinkage is associated with an increase in diffusion channels and hence to an increase in mean diffusivity of the grey matter (Fig. 4), which is observed in elderly humans with diffusion tensor imaging [173].

To summarise, ageing is accompanied with changes in gene expression and structure of astrocytes; these changes are region-specific and multifaceted. Increase in expression of GFAP and increase in astroglial cytoskeleton appears in some parts of the brain, notably in hippocampus. These changes, however, do not signal increase in astrocytic reactivity but may reflect long-term adaptive changes. At the same time, the complexity and full expend of astroglial arborisation seem to decrease in old brains, which also reduces the glial contribution to neuropil underlying an increase in the diffusivity of the grey matter. These structural changes coincide with functional decline of astroglia discussed in the ensuing chapters.

\section{Ageing astrocytes: Physiology}

Astroglial physiology is defined by highly hyperpolarized $(-80$ to $-85 \mathrm{mV})$ resting membrane potential, by inability to generate action potentials, by high activity of plasmalemmal transporters underlying astroglial homoeostatic responses and by intracellular ionic excitability [204]. Astroglial membrane potential lies close to the equilibrium potential for $\mathrm{K}^{+}$ions; astroglial membrane behaves as an almost ideal $\mathrm{K}^{+}$ electrode because of high density of several types of $\mathrm{K}^{+}$channels (inward and delayed rectifying, voltage-dependent and voltage independent $[135 ; 178 ; 208])$, which ensure the stability of membrane potential even upon substantial depolarising stimuli. Gap junction connectivity of astrocytes also contributes to the isopotentiality of astroglial syncytia [105] and astrocyte input resistance [1;153]. Steep transmembrane voltage and ionic gradients provide an electro-chemical driving force for homoeostatic transporters localised in astroglial membrane; most of these transporters are controlled by transmembrane gradient for $\mathrm{Na}^{+}[88 ; 207]$ and can be affected by $\mathrm{K}^{+}$mediated membrane depolarisation [99]. Astroglial $\mathrm{Na}^{+} / \mathrm{K}^{+}$pump is of fundamental importance for maintaining both transmembrane ionic gradients and hyperpolarised membrane potential. Stimulation of astrocytes with mechanical or neurochemical means trigger complex changes in the intracellular ion concentrations; these ionic signals represent the substrate for glial excitability [204]. Astroglial $\mathrm{Ca}^{2+}$ and $\mathrm{Na}^{+}$signalling is well characterised $[168 ; 179]$ with astroglial $\mathrm{Na}^{+} / \mathrm{Ca}^{2+}$ exchangers linking both signalling systems together [169]. Signalling potential for other ions, including $\mathrm{K}^{+}$and $\mathrm{Cl}^{-}$, in astrocytes are now being considered [21;209]. 
The data on age-dependent changes in physiological properties of astrocytes are quite limited (Table 3). Neither resting membrane potential nor membrane input resistance of astrocytes in cortical astrocytes was affected by ageing (mice aged between 1 and 21 months) but input resistance somewhat increased in aged hippocampal astroglial cells (from 9-12 and 20 - 24 month) [97; 152]. This increase in input resistance may reflect both age-dependent astrocyte shrinkage and uncoupling through the gapjunctions. Astrocytes in aged brains of humans and rodents express functional receptors to neurotransmitters and generate $\mathrm{Ca}^{2+}$ signals in response to appropriate stimulation $[59 ; 97 ; 127]$. The density of AMPA, NMDA and P2X receptors as well as the density of plasmalemmal glutamate transporter currents demonstrates bellshaped age dependency (Fig. 5). There are some indications about aberrant $\mathrm{Ca}^{2+}$ signalling in aged astrocytes. In 20 months old mice, the spontaneous $\mathrm{Ca}^{2+}$ oscillations have been found to occur about 20 times more frequent than in young 2.5 months old controls [110]. There are also some indications of age-dependent decrease in ATP-induced astroglial $\mathrm{Ca}^{2+}$ responses [96]. Old astrocytes seem to weaken their syncytial organisation: substantial decrease in astroglial coupling was reported for both cortex and hippocampus of $20-27$-months old mice [150]. All in all, and even despite the scarcity of experimental data, we may conclude that physiological ageing does not substantially affect fundamental physiological mechanisms in astrocytes.

\section{Astroglial senescence: does it exist in the ageing brain?}

The cellular senescence which is defined as irreversible growth arrest accompanied with some specific changes in gene expression, in cellular phenotypes and in molecular markers. The senescence of various cell types has been demonstrated to increase in ageing, while manipulation with cellular senescence can accelerate or retard (at least some of) age-dependent processes $[7 ; 77 ; 125]$. Historically the concept of cellular senescence goes all the way back to 1881 when August Weismann suggested that "death takes place because a worn-out tissue cannot forever renew itself, and because a capacity for increase by means of cell division is not everlasting but finite" [216]. The restricted cell division capacity, which ceases, in culture, after $40-60$ divisions was experimentally proven by Leonard Heyflick [68] and "Hayflick limit" become a thoroughly popular term (this term was coined by Macfarlane Burnett [24]). At a functional level, the cellular senescence is linked to the "senescence-associated secretory phenotype" reflecting increased release of various proinflammatory factors, including growth factors, chemokines, cytokines and proteases $[33 ; 132]$. This phenomenon, in turn, complements the concept of "inflammageing" that regards ageing as a chronic immunopathology [53].

Most (if not all) of the evidence favouring astroglial senescence (recently overviewed by [31]) has been obtained in vitro, in malignant glial cells, in cell lines and in primary astrocytes. Primary cultured astrocytes in vitro demonstrated replicative senescence and expressed classical markers of cell senescence including $\beta$ - galactosidase activity expression of p21 expression, and p53-dependent growth arrest [49]. Cultured astrocytes from post-mortem sample of AD patients showed an increase in senescence markers p16 and p21 as well as replication arrest [15]; similarly, senescent astroglial phenotype was described in cells subjected to oxidative stress $[13 ; 185]$. Co-culturing senescent astrocytes with neurones revealed reduced astroglial homoeostatic support and neuroprotection [84; 148]. Can this in vitro evidence be translated to the in vivo brain and physiological ageing? This remains an 
unanswered question. Astrocytes are profoundly postmitotic cells, with very low rates of proliferation: astroglial proliferation has been documented for many brain regions albeit the percentage of proliferating astrocytes varies between $0.090 \%-0.30 \%$ in the cerebral cortex and $0.445 \%$ in the corpus callosum $[34 ; 56 ; 57]$. To summarise: the role of astroglial senescence in the ageing brain and its contribution to cognitive decline remains to be studied and contemplated before the final verdict can be made.

\section{Ageing astrocytes: Loss of functions}

Although basic physiology of astrocytes in the old brain does not seem to be substantially affected, there is a wealth of evidence for decline of certain vital astroglial functions with ageing (Fig. 6). This decrease in astroglial support may impact on neuronal performance, on synaptic transmission and neuroplasticity, on neuroprotection and supply of neurones with energy substrates. Thus, age-dependent asthenia of astrocytes contributes to cognitive decline of the senescent brain.

\section{Neurotransmitter homeostasis}

(i) Glutamate. Astrocytes are central elements for glutamate turnover in the brain. Neurones, which (in contrast to astrocytes) are unable to synthesise glutamate de novo from glucose, rely on astrocytes for continuous supply of glutamine [70; 176], which, after being transported to neurones through the complementary system of export and import glutamine transporters of SLC38A1-5 family, is converted into glutamate and subsequently into GABA to be used in neurotransmission. Astrocytes are also central for glutamate removal from the synaptic cleft through $\mathrm{Na}^{+}$-dependent excitatory amino acid transporters 1 and 2 (EAAT1/SLC1A6 and EAAT2/SLC1A2) which clear $\sim 80 \%$ of all glutamate released in the course of neurotransmission [35]. After being accumulated into astrocytes glutamate is converted to glutamine by glutamine synthetase $[131 ; 167]$ and glutamine is again transported to neurones. Thus astrocytes accomplish glutamate turnover through the operation of the glutamate (GABA)glutamine shuttle.

Ageing is generally accompanied with an increase of the ratio of glutamate to glutamine in the brain indicating possible abnormalities in the operation of the glutamate (GABA)-glutamine shuttle [45; 64]. Expression of astrocytic glutamate transporters as well as the efficacy of glutamate uptake is reduced in old $(24-27$ months old) rats when compared to young adults (3 - 5 months old) [154]. In 18 - 21 months old mice the glutamate transporter current density was only $\sim 10-15 \%$ of that in 6 months old animals; although there was no difference between old and very young (1 month old) mice (Fig. 5, [97]). The levels of glutamate synthetase was somewhat (not significantly) lower in the hippocampal astrocytes of 18 months old mice [134]. As alluded to before, aged astrocytes have diminished peripheral and perisynaptic processes; this decreased synaptic coverage may also contribute to the reduced efficacy of astroglial glutamate uptake, increased spillover with subsequent impairment of synaptic plasticity [152].

(ii) Noradrenaline. Astroglial cells are central for catabolism of noradrenaline and other catecholamines because the principal enzyme monoaminoxidase-B (MAO-B) is mainly present in protoplasmic and radial astrocytes $[103 ; 217]$. The level of MAO-B in aged brain is increased two to three fold [95], which may have several damaging 
consequences. First, increase in MAO-B decreases the levels of noradrenaline; the noradrenergic excitation is provided by neurones from locus coreuleus, which is particularly vulnerable to age-dependent neurodegeneration. Increase in MAO-B therefore may exacerbate potential harmful effects of reduced noradrenergic innervation and hence potentially aggravate neurodegeneration [226]. Second, the major by-product of MAO-B is hydrogen peroxide, which gives rise to highly toxic hydroxyl radicals thus exacerbating the oxidative stress and damaging neurones [191].

(iii) $\gamma$-aminobutyric acid (GABA). Another consequence of elevated MAO-B content in aged astrocytes is linked to synthesis of main inhibitory neurotransmitter GABA. Healthy astrocytes do not have GABA synthesising enzymes and even when GABA is accumulated through dedicated transporters it is rapidly consumed by Krebs cycle [177]. Astrocytic GABA is increased in aged astrocytes and especially in astrocytes from $\mathrm{AD}$ patients and $\mathrm{AD}$ animal models [19; 100; 222], Thus may be linked to increase in MAO-B catalysed GABA production from putrescine. Astroglial GABA can be released through reversed GABA transporters or by diffusion through Bestrophine- $1 \mathrm{Cl}^{-}$channels thus contributing to neurotransmitter imbalance and negatively impacting on cognition [54; 79], although the latter mechanism is debatable and is frequently questioned [137].

\section{Neurogliovascular unit and the blood-brain barrier}

Protoplasmic astrocytes parcellate the nervous tissue into spatially segregated territorial domains [25]. Within these domains astrocytes integrate neurones, synapses, microglial cells and neighbouring capillaries into the neurogliovascular (or neurovascular) unit [72]. Astroglial endfeet form perivascular glia limitans that provide for parenchymal coverage of blood vessels in the brain. At the level of intraparenchymal arterioles and capillaries astrocytes contribute to the regulation of local blood flow through the release of vasoconstrictors and vasodilatators $[52 ; 124 ; 225]$. In particular, vasoactive agents are related to the activity of $\mathrm{Ca}^{2+}$-sensitive phospholipase A2 that produces arachidonic acid; the latter is converted to prostaglandins and to epoxyeicosatrienoic acids. The exact mechanisms translating astrocytic $\mathrm{Ca}^{2+}$ signals into release of eicosanoids and regulation of functional hyperaemia remain debatable; in particular the role of fast local $\mathrm{Ca}^{2+}$ signals not associated with ER $\mathrm{Ca}^{2+}$ release has been proposed [140]. Astrocytes function as intracranial baroreceptors and control of arterial blood pressure, hence, brain blood flow [109]. Ageing reduces brain stiffness in old human in sex and region-specific manner [5] and affects viscoelastic properties of the human brain [171] The astrocytes atrophy may be also considered in this context as changes in brain viscoelastisity may affect astrocyte ability to monitor cerebral perfusion and control systemic circulation. This phenomenon can be linked to age-related hypertonia and consequently to heart diseases and stroke.

The blood-brain barrier (BBB) separates the circulation from the brain microenvironment and is formed by the continuous layer of specialized brain capillary endothelial cells. These cells are functionally coupled with other vascular (pericytes, vascular smooth muscle cells), and neural (neurones, astrocytes, microglia) cells constituting the neurogliovascular unit [193]. At the capillary level, endothelial cells, pericytes and astroglial endfeet share a common basement membrane. At the level of arterioles, two basement membranes, the parenchymal (in contact with astroglial 
endfeet) and vascular (in contact with endothelial cells) create the perivascular space used by glymphatic clearance pathway to eliminate waste products from brain parenchyma [214]. Astrocytes act in concert with other cells to support formation and integrity of the BBB and to ensure proper functioning of neurovascular and neurometabolic coupling mechanisms [193]. Energy requirements are not uniform throughout the brain and depend on the local neuronal activity. Neurovascular coupling ensure a rapid and localised on-demand increase of cerebral blood flow sufficient delivery of oxygen and glucose and simultaneous removal of metabolites such as lactic acid and carbon dioxide; the phenomenon generally known as functional hyperaemia $[89 ; 122 ; 170]$. At the level of arteries and arteriolae, local blood flow is mainly regulated by the nitric oxide produced by neurones, whereas at the level of capillaries vasoconstriction and vasodilatation are regulated by both neuronal and astroglial mechanisms. Neurovascular coupling is tightly coordinated with dynamic metabolic changes regulating energy consumption and utilisation of metabolites, a mechanism known as neurometabolic coupling [215]. It is becoming increasingly clear that mechanisms of neurovascular and neurometabolic coupling are tightly coordinated with mechanisms regulating $\mathrm{BBB}$ permeability to nutrients and toxins.

Brain ageing is associated with restructuring of blood vessels and decrease in blood supply [4]. This translates in declining oxygen supply and causes imbalance in neural cells metabolism [76]. There are some indications that ageing affects glial secretion of arachidonic acid and eicosanoids, which may affect local neurovascular coupling [85; 197]. Another age-dependent mechanism may be associated with deficits in circulating levels of Insulin-like growth factor 1 (IGF-1), which promotes multiple cerebromicrovascular alterations [183]. Decrease in IGF-1 levels affect astrocytic eicosanoid production and hence may impair upon astroglial control of local functional hyperaemia [198].

Physiological brain ageing is accompanied with decay in BBB and disruption of neurovascular and neurometabolic coupling $[46 ; 118 ; 126]$, into which astroglial dysfunction most likely plays a major role. Ultrastructural studies of the BBB in aged rats showed increased thickness of capillary walls and basement membranes; furthermore, in the old animal the area of the astrocyte endfeet surrounding the capillaries was significantly higher than in the young animal [17]. There are also some indications that astrocytes loos their ability to regulate tight junctions expression in the context of neurodegeneration [94]; whether a similar loss of function occurs in physiological ageing remains to be investigated. In conclusion, brain ageing is accompanied by progressive decline in the BBB deterioration and accumulating evidence indicate that astroglial dysfunction plays complex and multifaceted role in this process. Future studies specifically focusing on the perivascular astroglial subpopulations may significantly improve our understanding about the role of astroglia during ageing-related BBB pathologies.

\section{Neurogenesis}

Neural stem cells which dwell and operate in the adult neurogenic niches of the subventricular zone and hippocampus are, in essence, radial astrocytes (also known as radial glia-like neural stem cells). These cells combine features of stem cells and homoeostatic astrocytes: they, for example, send processes to form perivascular 
endfeet and at the same time their peripheral processes provide for perisynaptic coverage $[117 ; 121]$. Ageing is associated with a significant decline in neurogenic capacity in all neurogenic zones due to a cessation of asymmetric division of radial stem astrocytes $[12 ; 18 ; 129]$. This neurogenic silencing may be associated with accumulation of damaged proteins [211]. Of note, pathological ageing and specifically Alzheimer disease, is associated with severe suppression of radial stem cell functions and in early decrease in neurogenesis [162; 165].

Control of proliferation of stem radial astrocytes also decreases with ageing and astrocytes contribute to this process. Astrocytes regulate, at least in part, asymmetric division of stem cells through Wnt-mediated survivin signalling and this regulation is compromised by ageing, leading to a decreased proliferative capacity [116]. Furthermore astroglial secretion of Wnt3 is reduced with ageing, disrupting the regulation of genes such as NeuroD1 and doublecortin [133]. These findings suggest that preservation of astrocytic functions play essential roles to protect hippocampal function during ageing process.

\section{Age-dependent decline of the glymphatic system}

Astrocytes are central elements of the brain specific glymphatic system responsible for life-long waste collection [73; 128]. Astroglial endfeet form the perivascular space and aquaporin 4 (AQP4) water channels localised in these endfeet mediate water transport into the brain parenchyma. Polarised expression of astroglial AQP4 which are concentrated in the endfeet is a key for normal operation of the glymphatic flow. In ageing, this polarisation is impaired and AQP4 channels migrate away from the endfeet which is associated with almost $40 \%$ decline in operational capacity of the glymphatic system [93]. Of note, even more severe decline is accompanying neurodegeneration and Alzheimer's disease in particular [147].

\section{Ageing impairs astroglial metabolic support}

Ageing increases astroglial in oxidative metabolism, which may limit their ability to supply neurones with metabolic substrates [78]. Furthermore, there are indications that ageing reduces astroglial ability to produce lactate and hence to operate lactate shuttle [63].

\section{Ageing astrocytes and mitochondria}

Decline in mitochondrial function in ageing is well documented [142;159], and the mitochondrial, as well as closely associated ROS, theories of ageing is generally accepted [192]. Mitochondrial ageing is associated with an increase in mutations of mtRNA and overall decline in mitochondrial energy production capacity. Mitochondrial failure obviously has grave repercussions for energy-demanding neural tissue. Data emerging in recent years indicate that astrocytes contribute to disposal of neuronal mitochondria. The latter are translocated into astroglial cells where they are disposed off through mitophagy. This transcellular mitochondrial degradation has been named "transmitophagy" [39]. Not only astrocytes degrade neuronal damaged mitochondria, but they supply neurones with functional mitochondria which assist energy production in stressed neurones for example in conditions of ischaemic insult 
[66]. Age-dependent astroglial dystrophy and decline in astroglial homoeostatic capabilities may supposedly, affect this pathway thus diminishing neuroprotection.

\section{Cholesterol synthesis}

The brain relies entirely on cholesterol synthesised in situ, because blood-brain barrier does not permit cholesterol transport [42]. Astrocytes are the source of cholesterol needed for synaptogenesis and morphological plasticity of neurones and astroglial synthesis of cholesterol seems to be the limiting factor regulating synapse formation [113]. In ageing the main cholesterol synthesising enzyme HMG-CoA reductase or Hmgcr, is down-regulated; at the same time the level of the receptors for cholesterol transport in astrocytes is increasing [16], indicating disrupted cholesterol homoeostasis that may impair synaptic plasticity [141].

\section{Age-dependent decline of astroglial defensive capabilities}

Astrocytes are vital elements of the brain defensive system through both homoeostatic support and astroglial reactivity [143]. In particular, astroglial cells are fundamental for the brain antioxidant system utilising glutathione and ascorbic acid [107]. Glutathione synthesis in neurones requires cysteine or glutamylcysteine as obligatory precursors; both of which are shuttled from astrocytes. Astrocytes (in contrast to neurones) specifically express the $\mathrm{Sxc}^{-}$glutamate/cystine exchanger [22] and thus can accumulate cystine; this latter is reduced to cysteine or converted into glutamylcysteine which can be utilised for gluthatione synthesis. Astrocytes secrete cysteine and gluthatione which is, when outside of the cell, converted into glutamylcysteine. Cysteine and glutamylcysteine are taken up by neurones; with cysteine in particular being transported by EAAT2/3 transporters [30]. Thus, without astrocytes neuronal glutathione production suffers because of the luck of substrate. Removal of astrocytes from neuronal-astroglial co-cultures substantially reduces neuronal gluthatione production, which facilitates neuronal oxidative damage. It was estimated that in co-culture an individual astrocyte was able to provide antioxidative protection to $\sim 20$ neurones [41]. Ageing is associated with decrease in the brain levels of glutathione most likely because of decreased production in astrocytes [48; 106]. In a toxic model of ageing and neurodegeneration that used chronic injection of d-galactose resulting in impaired memory and learning, astrocytes demonstrated signs of substantial damage, associated with decreased level of reduced glutathione and oxidative damage [101].

Reactive astrogliosis, as has been alluded above, is a specific defensive programme of astroglia, while deficits in reactive astroglial response are known to exacerbate neuropathology [143]. It has been suggested that age-dependent decrease in reactive capabilities of astrocytes and microglia, the glial paralysis, facilitates the development of neurodegenerative diseases and Alzheimer disease in particular [202]. Early stages of Alzheimer's disease, associated with mild cognitive impairment, are characterised with an increased astrogliosis $[27 ; 160]$. Conversely, advanced stages manifested by dementia are associated with decrease in astroglial reactivity: in general, demented brains have less reactive astrocytes $[111 ; 160]$. In depth analysis of nervous tissue of patients with Alzheimer disease pathology associated with cognitive preservation or with dementias revealed, in the latter group, idiosyncratic reactive astrocytes with thick and long processes and with an increased level of expression of glutamate 
transporter EAAT2 [91]. Ageing also disrupts reactive astrogliotic response to the traumatic brain injury; furthermore, aged astrocytes are much more susceptible to trauma induced rapid degeneration ultimately ending in clasmatodendrosis [47]. Finally, aged astrocytes whether in homoeostatic or in reactive state, fail to support remyelination further exacerbating the course of pathology in old age [156].

To summarise, ageing significantly decreases defensive and neuroprotective capacity of astrocytes thus increasing brain vulnerability to acute lesions and chronic pathologies including neurodegeneration.

\section{Lifestyle changes such as environmental stimulation and dieting promote astrocytes complexity and prolong cognitive ageing}

Environmental stimulation, combined with physical activity, social interactions, and richness of visual and sensory stimuli, represents the most powerful non-invasive and non-pharmacological approach to mitigate neurological conditions associated with ageing. Keeping people physically, mentally and socially fit prolongs cognitive longevity, while the brain subjecting to enriched environment undergoes a series of molecular, cellular, and structural changes conferring a greater capacity to withstand cognitive decline imposed by the normal ageing and age-associated diseases $[36 ; 102$; $119 ; 120]$. Furthermore, polytherapies, which include physical exercise and intellectual engagement, have demonstrated positive results in restoring cognitive abilities and ameliorate psychiatric symptoms in patients with Alzheimer's disease associated cognitive deficits [20;115].

Experimental data accumulated over recent decade demonstrate that environmental enrichment, physical activity or their combinations increase astroglial cells size, complexity, and expression of GFAP at the same time improving cognitive processes in animals (Table 4) thus suggesting astrocytic plasticity as a potential target and executor of environmental stimulation [43; 175]. Exposure to environmental enrichment and physical activity demonstrate a complex effect of astrocyte morphology in hippocampus: it boosts cell complexity by increasing length and number of primary branches and ramifications, which developed in parallel with an increase in the number of synaptic contacts $[43 ; 212]$. In aged $3 \times T$ Tg-AD mice model, environmental stimulus led to a significant increase of astroglial complexity, completely reversing morphological atrophy found early stages of $\mathrm{AD}$ and potentially related to synapse deficiency and cognitive abnormalities [164]. In the same study, environmental enrichment increased the size and complexity of astrocytes from healthy control mice. In another AD model, in the PDAPP-J20 transgenic mice, enriched environment from 5 to 8 months old increased the complexity of atrophic astrocytes located away from senile plaques and decreased the complexity (i.e. decreased reactivity) of plaque-associated astroglial cells [10]. Similarly, enriched environment increased astroglial complexity and improved cognitive performance even in advanced ages, when compared to animals housed in standard conditions [175]. Finally, enriched environment and physical exercise significantly improve the proliferative capacity of radial stem astrocytes thus rescuing neurogenesis in both normal ageing and in neurodegeneration [163].

Another important lifestyle factor impacting upon cognitive longevity and affecting morphological and functional properties of astroglia is associated with food intake 
and dieting. Caloric restriction received particular attention as limiting food intake while preserving healthy nutrition is known to prolong life span of many species from worms to primates and improve health [112]. Exposure of mice to classically restricted diet boost astroglial complexity by increasing the volume of peripheral processes thus increasing synaptic coverage. This in turn increased the efficacy of astrocytic $\mathrm{K}^{+}$buffering and glutamate uptake and limited glutamate spillover which improved synaptic plasticity [153].

To conclude, changes in lifestyle that include healthy and moderate diet, physical activity, increased intellectual engagement and social exposure all improve cognitive longevity; these interventions also improved astroglial homoeostatic capacity that may increase neural reserve and neural compensation thus contributing to the healthy ageing.

\section{Conclusions}

The cognitive longevity is directly determined by the cognitive reserve, which originates from life-long interaction of the environment and genome. Experiences of life, intellectual engagement and physical exercise, caloric regime and healthy diet all these factors define the brain ageing, the ability of the brain to withstand pathological attacks and its ability to counteract neurodegeneration which frequently develops at advanced age. Astrocytes, being the primary homoeostatic and defensive elements of the brain contribute to the maintenances of cognitive reserve through multiple mechanisms. Brain ageing is accompanied with progressive decrease in astroglial functional capacity; when the loss of function integrates the probability of pathological switch in the ageing process is increasing. Astroglial function can be maintained through the adoption of ageing friendly lifestyle; with "cerebral gymnastics" promoted by Ramon y Cajal [155] playing a specific role in cognitive preservation of the human brain. To conclude this essay we shall again quote the author of the "Old age" describing the high activity of old people, which, without doubt, is a key factor in keeping the brain alert and well throughout the lifespan given by nature to mankind.

"it is satisfactory to note how many of the very aged are in good possession of their mental faculties, taking a keen interest in passing events, forming a clear judgment upon them, and full of thought for the present and future welfare of others. It is no less satisfactory to find that the active, even severe and long-continued, functional activity of the matured brain seems in no way to impair its enduring qualities, and that good, earnest, useful employment of body and mind are not only compatible with, but even conducive to, longevity."

\footnotetext{
${ }^{1}$ George Murray Humphry, 1889, The Old Age. The results of information received respecting nearly nine hundred persons who had attained the age of eighty years, including seventy-four centenarians. MacMillan \& Bowes, Cambridge, p. 24
} 


\section{Acknowledgements}

AP and AV were supported by the Global Grant measure (No. 09.3.3-LMTK-

712-01-0082). MAO was supported by Conselho Nacional de Desenvolvimento Científico e Tecnológico (CNPq, Grant number 27724/2018-2) and Coordenação de Aperfeiçoamento de Pessoal de Nível Superior (CAPES, Grant number 88887.2005.00/2018-00). AS, AP and AB were supported by Russian Science Foundation grant 20-14-00241. 


\section{References}

1. Adermark, L., and Lovinger, D.M. (2008). Electrophysiological properties and gap junction coupling of striatal astrocytes. Neurochem Int 52; 1365-1372. doi: 10.1016/j.neuint.2008.02.006

2. Al-Dalahmah, O., Sosunov, A.A., Shaik, A., Ofori, K., Liu, Y., Vonsattel, J.P., Adorjan, I., Menon, V., and Goldman, J.E. (2020). Single-nucleus RNA-seq identifies Huntington disease astrocyte states. Acta Neuropathol Commun 8; 19. doi: 10.1186/s40478-020-0880-6

3. Amenta, F., Bronzetti, E., Sabbatini, M., and Vega, J.A. (1998). Astrocyte changes in aging cerebral cortex and hippocampus: a quantitative immunohistochemical study. Microsc Res Tech 43; 29-33. doi: 10.1002/(SICI)10970029(19981001)43:

4. Amin-Hanjani, S., Du, X., Pandey, D.K., Thulborn, K.R., and Charbel, F.T. (2015). Effect of age and vascular anatomy on blood flow in major cerebral vessels. $J$ Cereb Blood Flow Metab 35; 312-318. doi: 10.1038/jcbfm.2014.203

5. Arani, A., Murphy, M.C., Glaser, K.J., Manduca, A., Lake, D.S., Kruse, S.A., Jack, C.R., Jr., Ehman, R.L., and Huston, J., 3rd (2015). Measuring the effects of aging and sex on regional brain stiffness with MR elastography in healthy older adults. Neuroimage 111; 59-64. doi: 10.1016/j.neuroimage.2015.02.016

6. Augusto-Oliveira, M., Arrifano, G.P., Takeda, P.Y., Lopes-Araújo, A., SantosSacramento, L., Anthony, D.C., Verkhratsky, A., and Crespo-Lopez, M.E. (2020). Astroglia-specific contributions to the regulation of synapses, cognition and behaviour. Neurosci. Biobehav. Rev. 118; 331-357. doi: 10.1016/j.neubiorev.2020.07.039

7. Baker, D.J., Wijshake, T., Tchkonia, T., LeBrasseur, N.K., Childs, B.G., van de Sluis, B., Kirkland, J.L., and van Deursen, J.M. (2011). Clearance of p16Ink4apositive senescent cells delays ageing-associated disorders. Nature 479; 232-236. doi: 10.1038 /nature 10600

8. Bartzokis, G. (2011). Alzheimer's disease as homeostatic responses to agerelated myelin breakdown. Neurobiol Aging 32; 1341-1371. doi:

10.1016/j.neurobiolaging.2009.08.007

9. Bartzokis, G., Beckson, M., Lu, P.H., Nuechterlein, K.H., Edwards, N., and Mintz, J. (2001). Age-related changes in frontal and temporal lobe volumes in men: a magnetic resonance imaging study. Arch Gen Psychiatry 58; 461-465.

10. Beauquis, J., Pavia, P., Pomilio, C., Vinuesa, A., Podlutskaya, N., Galvan, V., and Saravia, F. (2013). Environmental enrichment prevents astroglial pathological changes in the hippocampus of APP transgenic mice, model of Alzheimer's disease. Exp Neurol 239; 28-37. doi: 10.1016/j.expneurol.2012.09.009

11. Becquet, D., Girardet, C., Guillaumond, F., Francois-Bellan, A.M., and Bosler, O. (2008). Ultrastructural plasticity in the rat suprachiasmatic nucleus. Possible involvement in clock entrainment. Glia 56; 294-305. doi: 10.1002/glia.20613

12. Ben Abdallah, N.M., Slomianka, L., Vyssotski, A.L., and Lipp, H.P. (2010). Early age-related changes in adult hippocampal neurogenesis in C57 mice. Neurobiol Aging 31; 151-161. doi: 10.1016/j.neurobiolaging.2008.03.002

13. Bitto, A., Sell, C., Crowe, E., Lorenzini, A., Malaguti, M., Hrelia, S., and Torres, C. (2010). Stress-induced senescence in human and rodent astrocytes. Exp Cell Res 316; 2961-2968. doi: 10.1016/j.yexcr.2010.06.021 
14. Bjorklund, H., Eriksdotter-Nilsson, M., Dahl, D., Rose, G., Hoffer, B., and

Olson, L. (1985). Image analysis of GFA-positive astrocytes from adolescence to senescence. Exp Brain Res 58; 163-170. doi: 10.1007/BF00238964

15. Blasko, I., Stampfer-Kountchev, M., Robatscher, P., Veerhuis, R., Eikelenboom, P., and Grubeck-Loebenstein, B. (2004). How chronic inflammation can affect the brain and support the development of Alzheimer's disease in old age: the role of microglia and astrocytes. Aging Cell 3; 169-176. doi: 10.1111/j.14749728.2004.00101.x

16. Boisvert, M.M., Erikson, G.A., Shokhirev, M.N., and Allen, N.J. (2018). The Aging Astrocyte Transcriptome from Multiple Regions of the Mouse Brain. Cell Rep 22; 269-285. doi: 10.1016/j.celrep.2017.12.039

17. Bors, L., Toth, K., Toth, E.Z., Bajza, A., Csorba, A., Szigeti, K., Mathe, D., Perlaki, G., Orsi, G., Toth, G.K., and Erdo, F. (2018). Age-dependent changes at the blood-brain barrier. A Comparative structural and functional study in young adult and middle aged rats. Brain Res Bull 139; 269-277. doi:

10.1016/j.brainresbull.2018.03.001

18. Bouab, M., Paliouras, G.N., Aumont, A., Forest-Berard, K., and Fernandes, K.J. (2011). Aging of the subventricular zone neural stem cell niche: evidence for quiescence-associated changes between early and mid-adulthood. Neuroscience 173; 135-149. doi: 10.1016/j.neuroscience.2010.11.032

19. Brawek, B., Chesters, R., Klement, D., Muller, J., Lerdkrai, C., Hermes, M., and Garaschuk, O. (2018). A bell-shaped dependence between amyloidosis and GABA accumulation in astrocytes in a mouse model of Alzheimer's disease. Neurobiol Aging 61; 187-197. doi: 10.1016/j.neurobiolaging.2017.09.028 20. Bredesen, D.E. (2014). Reversal of cognitive decline: a novel therapeutic program. Aging (Albany NY) 6; 707-717. doi: 10.18632/aging.100690

21. Breslin, K., Wade, J.J., Wong-Lin, K., Harkin, J., Flanagan, B., Van Zalinge, H., Hall, S., Walker, M., Verkhratsky, A., and McDaid, L. (2018). Potassium and sodium microdomains in thin astroglial processes: A computational model study. PLoS Comput Biol 14; e1006151. doi: 10.1371/journal.pcbi.1006151

22. Bridges, R.J., Natale, N.R., and Patel, S.A. (2012). System xc ${ }^{-}$ cystine/glutamate antiporter: an update on molecular pharmacology and roles within the CNS. Br J Pharmacol 165; 20-34. doi: 10.1111/j.1476-5381.2011.01480.x 23. Brothers, H.M., Bardou, I., Hopp, S.C., Kaercher, R.M., Corona, A.W., Fenn, A.M., Godbout, J.P., and Wenk, G.L. (2013). Riluzole partially rescues ageassociated, but not LPS-induced, loss of glutamate transporters and spatial memory. $J$ Neuroimmune Pharmacol 8; 1098-1105. doi: 10.1007/s11481-013-9476-2

24. Burnett, M. (1974). Intrinsic Mutagenesis. (Lancaster: Medical and Technical Publishing Co).

25. Bushong, E.A., Martone, M.E., Jones, Y.Z., and Ellisman, M.H. (2002).

Protoplasmic astrocytes in CA1 stratum radiatum occupy separate anatomical domains. J Neurosci 22; 183-192.

26. Butt, A.M., Papanikolaou, M., and Rivera, A. (2019). Physiology of Oligodendroglia. Adv Exp Med Biol 1175; 117-128. doi: 10.1007/978-981-13-991385

27. $\quad$ Carter, S.F., Scholl, M., Almkvist, O., Wall, A., Engler, H., Langstrom, B., and Nordberg, A. (2012). Evidence for astrocytosis in prodromal Alzheimer disease provided by ${ }^{11} \mathrm{C}$-deuterium-L-deprenyl: a multitracer PET paradigm combining ${ }^{11} \mathrm{C}$ Pittsburgh compound B and ${ }^{18} \mathrm{~F}-\mathrm{FDG}$. $J$ Nucl Med 53; 37-46. doi: 10.2967/jnumed.110.087031 
28. Castiglioni Jr., A.J., Legare, M.E., D.L., B., and Tiffany-Castiglioni, E. (1991).

Morphological changes in astrocytes of aging mice fed normal or caloric restricted diets. Age 14; 102-106. doi:

29. Cerbai, F., Lana, D., Nosi, D., Petkova-Kirova, P., Zecchi, S., Brothers, H.M., Wenk, G.L., and Giovannini, M.G. (2012). The neuron-astrocyte-microglia triad in normal brain ageing and in a model of neuroinflammation in the rat hippocampus. PLoS One 7; e45250. doi: 10.1371/journal.pone.0045250

30. Chen, Y., and Swanson, R.A. (2003). The glutamate transporters EAAT2 and EAAT3 mediate cysteine uptake in cortical neuron cultures. J Neurochem 84 ; 1332 1339.

31. Cohen, J., and Torres, C. (2019). Astrocyte senescence: Evidence and significance. Aging Cell 18; e12937. doi: 10.1111/acel.12937

32. Colombo, J.A., Quinn, B., and Puissant, V. (2002). Disruption of astroglial interlaminar processes in Alzheimer's disease. Brain Res Bull 58; 235-242. doi: 10.1016/s0361-9230(02)00785-2

33. Coppe, J.P., Desprez, P.Y., Krtolica, A., and Campisi, J. (2010). The senescence-associated secretory phenotype: the dark side of tumor suppression. Annu Rev Pathol 5; 99-118. doi: 10.1146/annurev-pathol-121808-102144

34. Dalton, M.M., Hommes, O.R., and Leblond, C.P. (1968). Correlation of glial proliferation with age in the mouse brain. J Comp Neurol 134; 397-400. doi: $10.1002 /$ cne. 901340403

35. Danbolt, N.C. (2001). Glutamate uptake. Prog Neurobiol 65; 1-105. doi: 10.1016/s0301-0082(00)00067-8

36. Dause, T.J., and Kirby, E.D. (2019). Aging gracefully: social engagement joins exercise and enrichment as a key lifestyle factor in resistance to age-related cognitive decline. Neural Regen Res 14; 39-42. doi: 10.4103/1673-5374.243698 37. David, J.P., Ghozali, F., Fallet-Bianco, C., Wattez, A., Delaine, S., Boniface, B., Di Menza, C., and Delacourte, A. (1997). Glial reaction in the hippocampal formation is highly correlated with aging in human brain. Neurosci Lett 235; 53-56. doi: 10.1016/s0304-3940(97)00708-8

38. Davies, D.S., Ma, J., Jegathees, T., and Goldsbury, C. (2017). Microglia show altered morphology and reduced arborization in human brain during aging and Alzheimer's disease. Brain Pathol 27; 795-808. doi: 10.1111/bpa. 12456 39. Davis, C.H., Kim, K.Y., Bushong, E.A., Mills, E.A., Boassa, D., Shih, T., Kinebuchi, M., Phan, S., Zhou, Y., Bihlmeyer, N.A., Nguyen, J.V., Jin, Y., Ellisman, M.H., and Marsh-Armstrong, N. (2014). Transcellular degradation of axonal mitochondria. Proc Natl Acad Sci U S A 111; 9633-9638. doi:

10.1073/pnas. 1404651111

40. del Río-Hortega, P., and Penfield, W.G. (1927). Cerebral cicatrix: The reaction of neuroglia and microglia to brain wounds. Bull. John Hopkins Hosp, 41; 278-303.

41. Desagher, S., Glowinski, J., and Premont, J. (1996). Astrocytes protect neurons from hydrogen peroxide toxicity. J Neurosci 16; 2553-2562.

42. Dietschy, J.M., and Turley, S.D. (2001). Cholesterol metabolism in the brain. Curr Opin Lipidol 12; 105-112. doi: 10.1097/00041433-200104000-00003

43. Diniz, D.G., de Oliveira, M.A., de Lima, C.M., Foro, C.A., Sosthenes, M.C., Bento-Torres, J., da Costa Vasconcelos, P.F., Anthony, D.C., and Diniz, C.W. (2016). Age, environment, object recognition and morphological diversity of GFAPimmunolabeled astrocytes. Behav Brain Funct 12; 28. doi: 10.1186/s12993-016-01112 
44. Diniz, D.G., Foro, C.A., Rego, C.M., Gloria, D.A., de Oliveira, F.R., Paes, J.M., de Sousa, A.A., Tokuhashi, T.P., Trindade, L.S., Turiel, M.C., Vasconcelos, E.G., Torres, J.B., Cunnigham, C., Perry, V.H., Vasconcelos, P.F., and Diniz, C.W. (2010). Environmental impoverishment and aging alter object recognition, spatial learning, and dentate gyrus astrocytes. Eur J Neurosci 32; 509-519. doi:

10.1111/j.1460-9568.2010.07296.x

45. Duarte, J.M., Do, K.Q., and Gruetter, R. (2014). Longitudinal neurochemical modifications in the aging mouse brain measured in vivo by $1 \mathrm{H}$ magnetic resonance spectroscopy. Neurobiol Aging 35; 1660-1668. doi:

10.1016/j.neurobiolaging.2014.01.135

46. Duncombe, J., Lennen, R.J., Jansen, M.A., Marshall, I., Wardlaw, J.M., and Horsburgh, K. (2017). Ageing causes prominent neurovascular dysfunction associated with loss of astrocytic contacts and gliosis. Neuropathol Appl Neurobiol 43; 477-491. doi: 10.1111/nan.12375

47. Early, A.N., Gorman, A.A., Van Eldik, L.J., Bachstetter, A.D., and Morganti, J.M. (2020). Effects of advanced age upon astrocyte-specific responses to acute traumatic brain injury in mice. J Neuroinflammation 17 ; 115 . doi: 10.1186/s12974020-01800-w

48. Emir, U.E., Raatz, S., McPherson, S., Hodges, J.S., Torkelson, C., Tawfik, P., White, T., and Terpstra, M. (2011). Noninvasive quantification of ascorbate and glutathione concentration in the elderly human brain. NMR Biomed 24; 888-894. doi: 10.1002/nbm. 1646

49. Evans, R.J., Wyllie, F.S., Wynford-Thomas, D., Kipling, D., and Jones, C.J. (2003). A P53-dependent, telomere-independent proliferative life span barrier in human astrocytes consistent with the molecular genetics of glioma development. Cancer Res 63; 4854-4861.

50. Fabricius, K., Jacobsen, J.S., and Pakkenberg, B. (2013). Effect of age on neocortical brain cells in $90+$ year old human females--a cell counting study.

Neurobiol Aging 34; 91-99. doi: 10.1016/j.neurobiolaging.2012.06.009

51. Ferrer, I. (2017). Diversity of astroglial responses across human neurodegenerative disorders and brain aging. Brain Pathol 27; 645-674. doi: $10.1111 /$ bpa.12538

52. Filosa, J.A., Bonev, A.D., Straub, S.V., Meredith, A.L., Wilkerson, M.K., Aldrich, R.W., and Nelson, M.T. (2006). Local potassium signaling couples neuronal activity to vasodilation in the brain. Nat Neurosci 9; 1397-1403. doi: 10.1038/nn1779 53. Franceschi, C., Capri, M., Monti, D., Giunta, S., Olivieri, F., Sevini, F., Panourgia, M.P., Invidia, L., Celani, L., Scurti, M., Cevenini, E., Castellani, G.C., and Salvioli, S. (2007). Inflammaging and anti-inflammaging: a systemic perspective on aging and longevity emerged from studies in humans. Mech Ageing Dev 128; 92-105. doi: 10.1016/j.mad.2006.11.016

54. Garaschuk, O., and Verkhratsky, A. (2019). GABAergic astrocytes in Alzheimer's disease. Aging (Albany NY) 11; 1602-1604. doi: 10.18632/aging.101870

55. Gavrilov, N., Golyagina, I., Brazhe, A., Scimemi, A., Turlapov, V., and Semyanov, A. (2018). Astrocytic Coverage of Dendritic Spines, Dendritic Shafts, and Axonal Boutons in Hippocampal Neuropil. Front Cell Neurosci 12; 248. doi: 10.3389/fncel.2018.00248

56. Ge, W.P., and Jia, J.M. (2016). Local production of astrocytes in the cerebral cortex. Neuroscience 323; 3-9. doi: 10.1016/j.neuroscience.2015.08.057 
57. Ge, W.P., Miyawaki, A., Gage, F.H., Jan, Y.N., and Jan, L.Y. (2012). Local generation of glia is a major astrocyte source in postnatal cortex. Nature 484; 376-380. doi: 10.1038/nature10959

58. Geinisman, Y., Bondareff, W., and Dodge, J.T. (1978). Hypertrophy of astroglial processes in the dentate gyrus of the senescent rat. Am J Anat 153; 537-543. doi: 10.1002/aja.1001530405

59. Gomez-Gonzalo, M., Martin-Fernandez, M., Martinez-Murillo, R., Mederos, S., Hernandez-Vivanco, A., Jamison, S., Fernandez, A.P., Serrano, J., Calero, P., Futch, H.S., Corpas, R., Sanfeliu, C., Perea, G., and Araque, A. (2017). Neuronastrocyte signaling is preserved in the aging brain. Glia $65 ; 569-580$. doi: 10.1002/glia.23112

60. Goss, J.R., Finch, C.E., and Morgan, D.G. (1991). Age-related changes in glial fibrillary acidic protein mRNA in the mouse brain. Neurobiol Aging 12; 165-170. doi: 10.1016/0197-4580(91)90056-p

61. Grubman, A., Chew, G., Ouyang, J.F., Sun, G., Choo, X.Y., McLean, C., Simmons, R.K., Buckberry, S., Vargas-Landin, D.B., Poppe, D., Pflueger, J., Lister, R., Rackham, O.J.L., Petretto, E., and Polo, J.M. (2019). A single-cell atlas of entorhinal cortex from individuals with Alzheimer's disease reveals cell-type-specific gene expression regulation. Nat Neurosci 22; 2087-2097. doi: 10.1038/s41593-0190539-4

62. Hardy, R.N., Simsek, Z.D., Curry, B., Core, S.L., Beltz, T., Xue, B., Johnson, A.K., Thunhorst, R.L., and Curtis, K.S. (2018). Aging affects isoproterenol-induced water drinking, astrocyte density, and central neuronal activation in female Brown Norway rats. Physiol Behav 192; 90-97. doi: 10.1016/j.physbeh.2018.03.005

63. Harris, J.L., Choi, I.Y., and Brooks, W.M. (2015). Probing astrocyte metabolism in vivo: proton magnetic resonance spectroscopy in the injured and aging brain. Front Aging Neurosci 7; 202. doi: 10.3389/fnagi.2015.00202

64. Harris, J.L., Yeh, H.W., Swerdlow, R.H., Choi, I.Y., Lee, P., and Brooks, W.M. (2014). High-field proton magnetic resonance spectroscopy reveals metabolic effects of normal brain aging. Neurobiol Aging 35; 1686-1694. doi:

10.1016/j.neurobiolaging.2014.01.018

65. Haug, H., and Eggers, R. (1991). Morphometry of the human cortex cerebri and corpus striatum during aging. Neurobiol Aging 12; 336-338; discussion 352-335. 66. Hayakawa, K., Esposito, E., Wang, X., Terasaki, Y., Liu, Y., Xing, C., Ji, X., and Lo, E.H. (2016). Transfer of mitochondria from astrocytes to neurons after stroke. Nature 535; 551-555. doi: 10.1038/nature 18928

67. Hayakawa, N., Kato, H., and Araki, T. (2007). Age-related changes of astorocytes, oligodendrocytes and microglia in the mouse hippocampal CA1 sector. Mech Ageing Dev 128; 311-316. doi: 10.1016/j.mad.2007.01.005

68. Hayflick, L., and Moorhead, P.S. (1961). The serial cultivation of human diploid cell strains. Exp Cell Res 25; 585-621. doi: 10.1016/0014-4827(61)90192-6 69. Henrik Heiland, D., Ravi, V.M., Behringer, S.P., Frenking, J.H., Wurm, J., Joseph, K., Garrelfs, N.W.C., Strahle, J., Heynckes, S., Grauvogel, J., Franco, P., Mader, I., Schneider, M., Potthoff, A.L., Delev, D., Hofmann, U.G., Fung, C., Beck, J., Sankowski, R., Prinz, M., and Schnell, O. (2019). Tumor-associated reactive astrocytes aid the evolution of immunosuppressive environment in glioblastoma. Nat Commun 10; 2541. doi: 10.1038/s41467-019-10493-6

70. Hertz, L., Dringen, R., Schousboe, A., and Robinson, S.R. (1999). Astrocytes: glutamate producers for neurons. J Neurosci Res 57; 417-428. 
71. Hulse, R.E., Winterfield, J., Kunkler, P.E., and Kraig, R.P. (2001). Astrocytic

clasmatodendrosis in hippocampal organ culture. Glia 33; 169-179. doi:

10.1002/1098-1136(200102)33:2<169::aid-glia1016>3.0.co;2-b

72. Iadecola, C. (2017). The Neurovascular Unit Coming of Age: A Journey through Neurovascular Coupling in Health and Disease. Neuron 96; 17-42. doi: 10.1016/j.neuron.2017.07.030

73. Iliff, J.J., Wang, M., Liao, Y., Plogg, B.A., Peng, W., Gundersen, G.A., Benveniste, H., Vates, G.E., Deane, R., Goldman, S.A., Nagelhus, E.A., and Nedergaard, M. (2012). A paravascular pathway facilitates CSF flow through the brain parenchyma and the clearance of interstitial solutes, including amyloid beta. $S c i$ Transl Med 4; 147ra111. doi: 10.1126/scitranslmed.3003748 74. Itoh, N., Itoh, Y., Tassoni, A., Ren, E., Kaito, M., Ohno, A., Ao, Y., Farkhondeh, V., Johnsonbaugh, H., Burda, J., Sofroniew, M.V., and Voskuhl, R.R. (2018). Cell-specific and region-specific transcriptomics in the multiple sclerosis model: Focus on astrocytes. Proc Natl Acad Sci U S A 115; E302-E309. doi: 10.1073/pnas. 1716032115

75. Jackson, F.R. (2011). Glial cell modulation of circadian rhythms. Glia 59; 1341-1350. doi: 10.1002/glia.21097

76. Jessen, S.B., Mathiesen, C., Lind, B.L., and Lauritzen, M. (2017). Interneuron Deficit Associates Attenuated Network Synchronization to Mismatch of Energy Supply and Demand in Aging Mouse Brains. Cereb Cortex 27; 646-659. doi: 10.1093/cercor/bhv261

77. Jeyapalan, J.C., and Sedivy, J.M. (2008). Cellular senescence and organismal aging. Mech Ageing Dev 129; 467-474. doi: 10.1016/j.mad.2008.04.001

78. Jiang, T., and Cadenas, E. (2014). Astrocytic metabolic and inflammatory changes as a function of age. Aging Cell. doi: 10.1111/acel.12268

79. Jo, S., Yarishkin, O., Hwang, Y.J., Chun, Y.E., Park, M., Woo, D.H., Bae, J.Y., Kim, T., Lee, J., Chun, H., Park, H.J., Lee, D.Y., Hong, J., Kim, H.Y., Oh, S.J., Park, S.J., Lee, H., Yoon, B.E., Kim, Y., Jeong, Y., Shim, I., Bae, Y.C., Cho, J., Kowall, N.W., Ryu, H., Hwang, E., Kim, D., and Lee, C.J. (2014). GABA from reactive astrocytes impairs memory in mouse models of Alzheimer's disease. Nat Med 20; 886-896. doi: $10.1038 / \mathrm{nm} .3639$

80. John Lin, C.C., Yu, K., Hatcher, A., Huang, T.W., Lee, H.K., Carlson, J., Weston, M.C., Chen, F., Zhang, Y., Zhu, W., Mohila, C.A., Ahmed, N., Patel, A.J., Arenkiel, B.R., Noebels, J.L., Creighton, C.J., and Deneen, B. (2017). Identification of diverse astrocyte populations and their malignant analogs. Nat Neurosci 20; 396405. doi: $10.1038 / \mathrm{nn} .4493$

81. Johnson, E.C.B., Dammer, E.B., Duong, D.M., Ping, L., Zhou, M., Yin, L., Higginbotham, L.A., Guajardo, A., White, B., Troncoso, J.C., Thambisetty, M., Montine, T.J., Lee, E.B., Trojanowski, J.Q., Beach, T.G., Reiman, E.M., Haroutunian, V., Wang, M., Schadt, E., Zhang, B., Dickson, D.W., Ertekin-Taner, N., Golde, T.E., Petyuk, V.A., De Jager, P.L., Bennett, D.A., Wingo, T.S., Rangaraju, S., Hajjar, I., Shulman, J.M., Lah, J.J., Levey, A.I., and Seyfried, N.T. (2020). Large-scale proteomic analysis of Alzheimer's disease brain and cerebrospinal fluid reveals early changes in energy metabolism associated with microglia and astrocyte activation. Nat Med 26; 769-780. doi: 10.1038/s41591-020-0815-6

82. Jyothi, H.J., Vidyadhara, D.J., Mahadevan, A., Philip, M., Parmar, S.K., Manohari, S.G., Shankar, S.K., Raju, T.R., and Alladi, P.A. (2015). Aging causes morphological alterations in astrocytes and microglia in human substantia nigra pars 
compacta. Neurobiol Aging 36; 3321-3333. doi:

10.1016/j.neurobiolaging.2015.08.024

83. Kanaan, N.M., Kordower, J.H., and Collier, T.J. (2010). Age-related changes in glial cells of dopamine midbrain subregions in rhesus monkeys. Neurobiol Aging 31; 937-952. doi: 10.1016/j.neurobiolaging.2008.07.006

84. Kawano, H., Katsurabayashi, S., Kakazu, Y., Yamashita, Y., Kubo, N., Kubo, M., Okuda, H., Takasaki, K., Kubota, K., Mishima, K., Fujiwara, M., Harata, N.C., and Iwasaki, K. (2012). Long-term culture of astrocytes attenuates the readily releasable pool of synaptic vesicles. PLoS One 7; e48034. doi:

10.1371/journal.pone.0048034

85. Keleshian, V.L., Modi, H.R., Rapoport, S.I., and Rao, J.S. (2013). Aging is associated with altered inflammatory, arachidonic acid cascade, and synaptic markers, influenced by epigenetic modifications, in the human frontal cortex. J Neurochem 125; 63-73. doi: $10.1111 /$ jnc. 12153

86. Kettenmann, H., Kirchhoff, F., and Verkhratsky, A. (2013). Microglia: new roles for the synaptic stripper. Neuron 77; 10-18. doi: 10.1016/j.neuron.2012.12.023 87. Kettenmann, H., and Ransom, B., eds. (2013). Neuroglia. (Oxford: Oxford Unversity Press).

88. Kirischuk, S., Parpura, V., and Verkhratsky, A. (2012). Sodium dynamics: another key to astroglial excitability? Trends Neurosci 35; 497-506. doi: 10.1016/j.tins.2012.04.003

89. Kisler, K., Nelson, A.R., Montagne, A., and Zlokovic, B.V. (2017). Cerebral blood flow regulation and neurovascular dysfunction in Alzheimer disease. Nat Rev Neurosci 18; 419-434. doi: 10.1038/nrn.2017.48

90. Klein, M., Lohr, C., and Droste, D. (2020). Age-Dependent Heterogeneity of Murine Olfactory Bulb Astrocytes. Front Aging Neurosci 12; 172. doi: 10.3389/fnagi.2020.00172

91. Kobayashi, E., Nakano, M., Kubota, K., Himuro, N., Mizoguchi, S., Chikenji, T., Otani, M., Mizue, Y., Nagaishi, K., and Fujimiya, M. (2018). Activated forms of astrocytes with higher GLT-1 expression are associated with cognitive normal subjects with Alzheimer pathology in human brain. Sci Rep 8; 1712. doi: 10.1038/s41598-018-19442-7

92. Kohama, S.G., Goss, J.R., Finch, C.E., and McNeill, T.H. (1995). Increases of glial fibrillary acidic protein in the aging female mouse brain. Neurobiol Aging 16; 59-67. doi: 10.1016/0197-4580(95)80008-f

93. Kress, B.T., Iliff, J.J., Xia, M., Wang, M., Wei, H.S., Zeppenfeld, D., Xie, L., Kang, H., Xu, Q., Liew, J.A., Plog, B.A., Ding, F., Deane, R., and Nedergaard, M. (2014). Impairment of paravascular clearance pathways in the aging brain. Ann Neurol 76; 845-861. doi: 10.1002/ana.24271

94. Kriauciunaite, K., Kausyle, A., Pajarskiene, J., Tunaitis, V., Lim, D., Verkhratsky, A., and Pivoriunas, A. (2020). Immortalised Hippocampal Astrocytes from 3xTG-AD Mice Fail to Support BBB Integrity In Vitro: Role of Extracellular Vesicles in Glial-Endothelial Communication. Cell Mol Neurobiol. doi: 10.1007/s10571-020-00871-w

95. Kumar, M.J., and Andersen, J.K. (2004). Perspectives on MAO-B in aging and neurological disease: where do we go from here? Mol Neurobiol 30; 77-89. doi: 10.1385/MN:30:1:077

96. Lalo, U., Bogdanov, A., and Pankratov, Y. (2019). Age- and ExperienceRelated Plasticity of ATP-Mediated Signaling in the Neocortex. Front Cell Neurosci 13; 242. doi: 10.3389/fncel.2019.00242 
97. Lalo, U., Palygin, O., North, R.A., Verkhratsky, A., and Pankratov, Y. (2011).

Age-dependent remodelling of ionotropic signalling in cortical astroglia. Aging Cell 10; 392-402. doi: $10.1111 / j .1474-9726.2011 .00682 . x$

98. Landfield, P.W., Rose, G., Sandles, L., Wohlstadter, T.C., and Lynch, G. (1977). Patterns of astroglial hypertrophy and neuronal degeneration in the hippocampus of ages, memory-deficient rats. $J$ Gerontol 32; 3-12. doi: $10.1093 /$ geronj $/ 32.1 .3$

99. Lebedeva, A., Plata, A., Nosova, O., Tyurikova, O., and Semyanov, A. (2018). Activity-dependent changes in transporter and potassium currents in hippocampal astrocytes. Brain Res Bull 136; 37-43. doi: 10.1016/j.brainresbull.2017.08.015 100. Lee, M., McGeer, E.G., and McGeer, P.L. (2011). Mechanisms of GABA release from human astrocytes. Glia 59; 1600-1611. doi: 10.1002/glia.21202 101. Lei, M., Hua, X., Xiao, M., Ding, J., Han, Q., and Hu, G. (2008). Impairments of astrocytes are involved in the d-galactose-induced brain aging. Biochem Biophys Res Commun 369; 1082-1087. doi: 10.1016/j.bbrc.2008.02.151

102. Leon, M., and Woo, C. (2018). Environmental Enrichment and Successful Aging. Front Behav Neurosci 12; 155. doi: 10.3389/fnbeh.2018.00155

103. Levitt, P., Pintar, J.E., and Breakefield, X.O. (1982). Immunocytochemical demonstration of monoamine oxidase $\mathrm{B}$ in brain astrocytes and serotonergic neurons. Proc Natl Acad Sci U S A 79; 6385-6389. doi: 10.1073/pnas.79.20.6385

104. Long, J.M., Kalehua, A.N., Muth, N.J., Calhoun, M.E., Jucker, M., Hengemihle, J.M., Ingram, D.K., and Mouton, P.R. (1998). Stereological analysis of astrocyte and microglia in aging mouse hippocampus. Neurobiol Aging 19; 497-503. doi: 10.1016/s0197-4580(98)00088-8

105. Ma, B., Buckalew, R., Du, Y., Kiyoshi, C.M., Alford, C.C., Wang, W., McTigue, D.M., Enyeart, J.J., Terman, D., and Zhou, M. (2016). Gap junction coupling confers isopotentiality on astrocyte syncytium. Glia 64; 214-226. doi: $10.1002 /$ glia. 22924

106. Maher, P. (2005). The effects of stress and aging on glutathione metabolism. Ageing Res Rev 4; 288-314. doi: 10.1016/j.arr.2005.02.005

107. Makar, T.K., Nedergaard, M., Preuss, A., Gelbard, A.S., Perumal, A.S., and Cooper, A.J. (1994). Vitamin E, ascorbate, glutathione, glutathione disulfide, and enzymes of glutathione metabolism in cultures of chick astrocytes and neurons: evidence that astrocytes play an important role in antioxidative processes in the brain. $J$ Neurochem 62; 45-53. doi:

108. Mansour, H., Chamberlain, C.G., Weible, M.W., 2nd, Hughes, S., Chu, Y., and Chan-Ling, T. (2008). Aging-related changes in astrocytes in the rat retina: imbalance between cell proliferation and cell death reduces astrocyte availability. Aging Cell 7; 526-540. doi: 10.1111/j.1474-9726.2008.00402.x

109. Marina, N., Christie, I.N., Korsak, A., Doronin, M., Brazhe, A., Hosford, P.S., Wells, J.A., Sheikhbahaei, S., Humoud, I., Paton, J.F.R., Lythgoe, M.F., Semyanov, A., Kasparov, S., and Gourine, A.V. (2020). Astrocytes monitor cerebral perfusion and control systemic circulation to maintain brain blood flow. Nat Commun 11; 131. doi: 10.1038/s41467-019-13956-y

110. Mathiesen, C., Brazhe, A., Thomsen, K., and Lauritzen, M. (2013).

Spontaneous calcium waves in Bergman glia increase with age and hypoxia and may reduce tissue oxygen. J Cereb Blood Flow Metab 33; 161-169. doi:

$10.1038 / \mathrm{jcbfm} .2012 .175$

111. Mathur, R., Ince, P.G., Minett, T., Garwood, C.J., Shaw, P.J., Matthews, F.E., Brayne, C., Simpson, J.E., Wharton, S.B., (2015). A reduced astrocyte response to 
beta-amyloid plaques in the ageing brain associates with cognitive impairment. PLoS One 10; e0118463. doi: 10.1371/journal.pone.0118463

112. Mattison, J.A., Colman, R.J., Beasley, T.M., Allison, D.B., Kemnitz, J.W., Roth, G.S., Ingram, D.K., Weindruch, R., de Cabo, R., and Anderson, R.M. (2017). Caloric restriction improves health and survival of rhesus monkeys. Nat Commun 8; 14063. doi: $10.1038 /$ ncomms 14063

113. Mauch, D.H., Nagler, K., Schumacher, S., Goritz, C., Muller, E.C., Otto, A., and Pfrieger, F.W. (2001). CNS synaptogenesis promoted by glia-derived cholesterol. Science 294; 1354-1357. doi: 10.1126/science.294.5545.1354

114. Medvedev, N., Popov, V., Henneberger, C., Kraev, I., Rusakov, D.A., and Stewart, M.G. (2014). Glia selectively approach synapses on thin dendritic spines. Philos Trans R Soc Lond B Biol Sci 369; 20140047. doi: 10.1098/rstb.2014.0047 115. Meng, Q., Lin, M.S., and Tzeng, I.S. (2020). Relationship Between Exercise and Alzheimer's Disease: A Narrative Literature Review. Front Neurosci 14; 131. doi: 10.3389/fnins.2020.00131

116. Miranda, C.J., Braun, L., Jiang, Y., Hester, M.E., Zhang, L., Riolo, M., Wang, H., Rao, M., Altura, R.A., and Kaspar, B.K. (2012). Aging brain microenvironment decreases hippocampal neurogenesis through Wnt-mediated survivin signaling. Aging Cell 11; 542-552. doi: 10.1111/j.1474-9726.2012.00816.x

117. Mirzadeh, Z., Merkle, F.T., Soriano-Navarro, M., Garcia-Verdugo, J.M., and Alvarez-Buylla, A. (2008). Neural stem cells confer unique pinwheel architecture to the ventricular surface in neurogenic regions of the adult brain. Cell Stem Cell 3; 265278. doi: 10.1016/j.stem.2008.07.004

118. Montagne, A., Barnes, S.R., Sweeney, M.D., Halliday, M.R., Sagare, A.P., Zhao, Z., Toga, A.W., Jacobs, R.E., Liu, C.Y., Amezcua, L., Harrington, M.G., Chui, H.C., Law, M., and Zlokovic, B.V. (2015). Blood-brain barrier breakdown in the aging human hippocampus. Neuron 85; 296-302. doi: 10.1016/j.neuron.2014.12.032

119. Mora, F. (2013). Successful brain aging: plasticity, environmental enrichment, and lifestyle. Dialogues Clin Neurosci 15; 45-52. doi:

120. Mora, F., Segovia, G., and del Arco, A. (2007). Aging, plasticity and environmental enrichment: structural changes and neurotransmitter dynamics in several areas of the brain. Brain Res Rev 55; 78-88. doi:

10.1016/j.brainresrev.2007.03.011

121. Moss, J., Gebara, E., Bushong, E.A., Sanchez-Pascual, I., O'Laoi, R., El M'Ghari, I., Kocher-Braissant, J., Ellisman, M.H., and Toni, N. (2016). Fine processes of Nestin-GFP-positive radial glia-like stem cells in the adult dentate gyrus ensheathe local synapses and vasculature. Proc Natl Acad Sci U S A 113; E2536-2545. doi: $10.1073 /$ pnas. 1514652113

122. Mosso, A. (1880). Sulla circolazione del sangue nel cervello dell'uomo. Mem. Real Acc. Lincei 5; 237-358. doi:

123. Mouton, P.R., Long, J.M., Lei, D.L., Howard, V., Jucker, M., Calhoun, M.E., and Ingram, D.K. (2002). Age and gender effects on microglia and astrocyte numbers in brains of mice. Brain Res 956; 30-35. doi: 10.1016/s0006-8993(02)03475-3

124. Mulligan, S.J., and MacVicar, B.A. (2004). Calcium transients in astrocyte endfeet cause cerebrovascular constrictions. Nature 431; 195-199. doi:

10.1038 /nature 02827

125. Munoz-Espin, D., and Serrano, M. (2014). Cellular senescence: from physiology to pathology. Nat Rev Mol Cell Biol 15; 482-496. doi: 10.1038/nrm3823 126. Nation, D.A., Sweeney, M.D., Montagne, A., Sagare, A.P., D'Orazio, L.M., Pachicano, M., Sepehrband, F., Nelson, A.R., Buennagel, D.P., Harrington, M.G., 
Benzinger, T.L.S., Fagan, A.M., Ringman, J.M., Schneider, L.S., Morris, J.C., Chui, H.C., Law, M., Toga, A.W., and Zlokovic, B.V. (2019). Blood-brain barrier breakdown is an early biomarker of human cognitive dysfunction. Nat Med 25; 270276. doi: 10.1038/s41591-018-0297-y

127. Navarrete, M., Perea, G., Maglio, L., Pastor, J., Garcia de Sola, R., and Araque, A. (2013). Astrocyte calcium signal and gliotransmission in human brain tissue. Cereb Cortex 23; 1240-1246. doi: 10.1093/cercor/bhs122

128. Nedergaard, M. (2013). Neuroscience. Garbage truck of the brain. Science 340; 1529-1530. doi: 10.1126/science. 1240514

129. Nicaise, A.M., Willis, C.M., Crocker, S.J., and Pluchino, S. (2020). Stem Cells of the Aging Brain. Front Aging Neurosci. 12; 247. doi:

130. Nichols, N.R., Day, J.R., Laping, N.J., Johnson, S.A., and Finch, C.E. (1993). GFAP mRNA increases with age in rat and human brain. Neurobiol Aging 14; 421429. doi: 10.1016/0197-4580(93)90100-p

131. Norenberg, M.D., and Martinez-Hernandez, A. (1979). Fine structural localization of glutamine synthetase in astrocytes of rat brain. Brain Res 161; 303-310. 132. Ohtani, N. (2019). Deciphering the mechanism for induction of senescenceassociated secretory phenotype (SASP) and its role in aging and cancer development. J Biochem. doi: 10.1093/jb/mvz055

133. Okamoto, M., Inoue, K., Iwamura, H., Terashima, K., Soya, H., Asashima, M., and Kuwabara, T. (2011). Reduction in paracrine Wnt3 factors during aging causes impaired adult neurogenesis. FASEB J 25; 3570-3582. doi: 10.1096/fj.11-184697 134. Olabarria, M., Noristani, H.N., Verkhratsky, A., and Rodriguez, J.J. (2011). Age-dependent decrease in glutamine synthetase expression in the hippocampal astroglia of the triple transgenic Alzheimer's disease mouse model: mechanism for deficient glutamatergic transmission? Mol Neurodegener 6; 55. doi: 10.1186/17501326-6-55

135. Olsen, M.L., Khakh, B.S., Skatchkov, S.N., Zhou, M., Lee, C.J., and Rouach, N. (2015). New Insights on Astrocyte Ion Channels: Critical for Homeostasis and Neuron-Glia Signaling. J Neurosci 35; 13827-13835. doi:

10.1523/JNEUROSCI.2603-15.2015

136. Olude, M.A., Mustapha, O.A., Aderounmu, O.A., Olopade, J.O., and Ihunwo, A.O. (2015). Astrocyte morphology, heterogeneity, and density in the developing African giant rat (Cricetomys gambianus). Front Neuroanat 9; 67. doi: 10.3389/fnana.2015.00067

137. Ormel, L., Lauritzen, K.H., Schreiber, R., Kunzelmann, K., and Gundersen, V. (2020). GABA, but Not Bestrophin-1, Is Localized in Astroglial Processes in the Mouse Hippocampus and the Cerebellum. Front Mol Neurosci 13; 135. doi:

138. Orre, M., Kamphuis, W., Osborn, L.M., Jansen, A.H.P., Kooijman, L., Bossers, K., and Hol, E.M. (2014). Isolation of glia from Alzheimer's mice reveals inflammation and dysfunction. Neurobiol Aging 35; 2746-2760. doi:

10.1016/j.neurobiolaging.2014.06.004

139. Orre, M., Kamphuis, W., Osborn, L.M., Melief, J., Kooijman, L., Huitinga, I., Klooster, J., Bossers, K., and Hol, E.M. (2014). Acute isolation and transcriptome characterization of cortical astrocytes and microglia from young and aged mice. Neurobiol Aging 35; 1-14. doi: 10.1016/j.neurobiolaging.2013.07.008 140. Otsu, Y., Couchman, K., Lyons, D.G., Collot, M., Agarwal, A., Mallet, J.M., Pfrieger, F.W., Bergles, D.E., and Charpak, S. (2015). Calcium dynamics in astrocyte processes during neurovascular coupling. Nat Neurosci 18; 210-218. doi: 10.1038/nn.3906 
141. Palmer, A.L., and Ousman, S.S. (2018). Astrocytes and Aging. Front Aging Neurosci 10; 337. doi: 10.3389/fnagi.2018.00337

142. Payne, B.A., and Chinnery, P.F. (2015). Mitochondrial dysfunction in aging: Much progress but many unresolved questions. Biochim Biophys Acta 1847; 13471353. doi: 10.1016/j.bbabio.2015.05.022

143. Pekny, M., Pekna, M., Messing, A., Steinhauser, C., Lee, J.M., Parpura, V., Hol, E.M., Sofroniew, M.V., and Verkhratsky, A. (2016). Astrocytes: a central element in neurological diseases. Acta Neuropathol 131; 323-345. doi:

10.1007/s00401-015-1513-1

144. Pekny, M., Wilhelmsson, U., and Pekna, M. (2014). The dual role of astrocyte activation and reactive gliosis. Neurosci Lett 565; 30-38. doi:

10.1016/j.neulet.2013.12.071

145. Pelvig, D.P., Pakkenberg, H., Stark, A.K., and Pakkenberg, B. (2008).

Neocortical glial cell numbers in human brains. Neurobiol Aging 29; 1754-1762. doi: 10.1016/j.neurobiolaging.2007.04.013

146. Penfield, W. (1928). Neuroglia and microglia-the interstitial tissue of the central nervous system. In Special cytology, the form and function of the cell in health and disease. E.V. Cowdry, ed. (New York: Hoeber), pp. 1033-1068.

147. Peng, W., Achariyar, T.M., Li, B., Liao, Y., Mestre, H., Hitomi, E., Regan, S., Kasper, T., Peng, S., Ding, F., Benveniste, H., Nedergaard, M., and Deane, R. (2016). Suppression of glymphatic fluid transport in a mouse model of Alzheimer's disease.

Neurobiol Dis 93; 215-225. doi: 10.1016/j.nbd.2016.05.015

148. Pertusa, M., Garcia-Matas, S., Rodriguez-Farre, E., Sanfeliu, C., and Cristofol, R. (2007). Astrocytes aged in vitro show a decreased neuroprotective capacity. $J$ Neurochem 101; 794-805. doi: 10.1111/j.1471-4159.2006.04369.x

149. Peters, A., and Sethares, C. (2004). Oligodendrocytes, their progenitors and other neuroglial cells in the aging primate cerebral cortex. Cereb Cortex 14; 995-1007. doi: $10.1093 /$ cercor/bhh060

150. Peters, O., Schipke, C.G., Philipps, A., Haas, B., Pannasch, U., Wang, L.P., Benedetti, B., Kingston, A.E., and Kettenmann, H. (2009). Astrocyte function is modified by Alzheimer's disease-like pathology in aged mice. J Alzheimers Dis 18; 177-189. doi: 10.3233/JAD-2009-1140

151. Plata, A., Lebedeva, A., Denisov, P., Nosova, O., Postnikova, T.Y., Pimashkin, A., Brazhe, A., Zaitsev, A.V., Rusakov, D.A., and Semyanov, A. (2018). Astrocytic Atrophy Following Status Epilepticus Parallels Reduced $\mathrm{Ca}^{2+}$ Activity and Impaired Synaptic Plasticity in the Rat Hippocampus. Front Mol Neurosci 11; 215. doi: 10.3389/fnmol.2018.00215

152. Popov, A., Brazhe, A., Denisov, P., Sutyagina, O., Lazareva, N., Verkhratsky, A., and Semyanov, A. (2020). Astrocytes dystrophy in ageing brain parallels impaired synaptic plasticity. bioRxiv. doi: 10.1101/2020.08.05.237420

153. Popov, A., Denisov, P., Bychkov, M., Brazhe, A., Lyukmanova, E., Shenkarev, Z., Lazareva, N., Verkhratsky, A., and Semyanov, A. (2020). Caloric restriction triggers morphofunctional remodeling of astrocytes and enhances synaptic plasticity in the mouse hippocampus. Cell Death Dis 11; 208. doi: 10.1038/s41419-020-2406-3 154. Potier, B., Billard, J.M., Riviere, S., Sinet, P.M., Denis, I., Champeil-Potokar, G., Grintal, B., Jouvenceau, A., Kollen, M., and Dutar, P. (2010). Reduction in glutamate uptake is associated with extrasynaptic NMDA and metabotropic glutamate receptor activation at the hippocampal CA1 synapse of aged rats. Aging Cell 9; 722735. doi: 10.1111/j.1474-9726.2010.00593.x 
155. Ramon-y-Cajal, S. (1892). El nuevo concepto de la histología de los centros nerviosos. Rev. Cienc. Méd. Barcelona 18; 361-376, 457,-476, 505,-520, 529-541. doi:

156. Rawji, K.S., Gonzalez Martinez, G.A., Sharma, A., and Franklin, R.J.M. (2020). The Role of Astrocytes in Remyelination. Trends Neurosci 43; 596-607. doi: 10.1016/j.tins.2020.05.006

157. Reichenbach, A., Derouiche, A., and Kirchhoff, F. (2010). Morphology and dynamics of perisynaptic glia. Brain Res Rev 63; 11-25. doi:

10.1016/j.brainresrev.2010.02.003

158. Robillard, K.N., Lee, K.M., Chiu, K.B., and MacLean, A.G. (2016). Glial cell morphological and density changes through the lifespan of rhesus macaques. Brain Behav Immun 55; 60-69. doi: 10.1016/j.bbi.2016.01.006

159. Rockstein, M., and Brandt, K.F. (1963). Enzyme changes in flight muscle correlated with aging and flight ability in the male housefly. Science 139; 1049-1051. doi: 10.1126/science.139.3559.1049

160. Rodriguez-Vieitez, E., Saint-Aubert, L., Carter, S.F., Almkvist, O., Farid, K., Scholl, M., Chiotis, K., Thordardottir, S., Graff, C., Wall, A., Langstrom, B., and Nordberg, A. (2016). Diverging longitudinal changes in astrocytosis and amyloid PET in autosomal dominant Alzheimer's disease. Brain 139; 922-936. doi: 10.1093/brain/awv404

161. Rodriguez, J.J., Butt, A.M., Gardenal, E., Parpura, V., and Verkhratsky, A. (2016). Complex and differential glial responses in Alzheimer's disease and ageing. Curr Alzheimer Res 13; 343-358. doi: 10.2174/1567205013666160229112911

162. Rodriguez, J.J., Jones, V.C., Tabuchi, M., Allan, S.M., Knight, E.M., LaFerla, F.M., Oddo, S., and Verkhratsky, A. (2008). Impaired adult neurogenesis in the dentate gyrus of a triple transgenic mouse model of Alzheimer's disease. PLoS One 3; e2935. doi: 10.1371/journal.pone.0002935

163. Rodriguez, J.J., Noristani, H.N., Olabarria, M., Fletcher, J., Somerville, T.D., Yeh, C.Y., and Verkhratsky, A. (2011). Voluntary running and environmental enrichment restores impaired hippocampal neurogenesis in a triple transgenic mouse model of Alzheimer's disease. Curr Alzheimer Res 8; 707-717. doi:

$10.2174 / 156720511797633214$

164. Rodriguez, J.J., Terzieva, S., Olabarria, M., Lanza, R.G., and Verkhratsky, A. (2013). Enriched environment and physical activity reverse astrogliodegeneration in the hippocampus of AD transgenic mice. Cell Death Dis 4; e678. doi: 10.1038 /cddis.2013.194

165. Rodriguez, J.J., and Verkhratsky, A. (2011). Neurogenesis in Alzheimer's disease. J Anat 219; 78-89. doi: 10.1111/j.1469-7580.2011.01343.x

166. Rodriguez, J.J., Yeh, C.Y., Terzieva, S., Olabarria, M., Kulijewicz-Nawrot, M., and Verkhratsky, A. (2014). Complex and region-specific changes in astroglial markers in the aging brain. Neurobiol Aging 35; 15-23. doi:

10.1016/j.neurobiolaging.2013.07.002

167. Rose, C.F., Verkhratsky, A., and Parpura, V. (2013). Astrocyte glutamine synthetase: pivotal in health and disease. Biochem Soc Trans 41; 1518-1524. doi: 10.1042/BST20130237

168. Rose, C.R., and Verkhratsky, A. (2016). Principles of sodium homeostasis and sodium signalling in astroglia. Glia 64; 1611-1627. doi: 10.1002/glia.22964

169. Rose, C.R., Ziemens, D., and Verkhratsky, A. (2020). On the special role of NCX in astrocytes: Translating $\mathrm{Na}^{+}$-transients into intracellular $\mathrm{Ca}^{2+}$ signals. Cell Calcium 86; 102154. doi: 10.1016/j.ceca.2019.102154 
170. Roy, C.S., and Sherrington, C.S. (1890). On the regulation of the blood-supply of the brain. J. Physiol. (Lond.) 11; 85-108. doi:

171. Sack, I., Streitberger, K.J., Krefting, D., Paul, F., and Braun, J. (2011). The influence of physiological aging and atrophy on brain viscoelastic properties in humans. PLoS One 6; e23451. doi: 10.1371/journal.pone.0023451

172. Sahlas, D.J., Bilbao, J.M., Swartz, R.H., and Black, S.E. (2002).

Clasmatodendrosis correlating with periventricular hyperintensity in mixed dementia. Ann Neurol 52; 378-381. doi: 10.1002/ana.10310

173. Salminen, L.E., Conturo, T.E., Laidlaw, D.H., Cabeen, R.P., Akbudak, E., Lane, E.M., Heaps, J.M., Bolzenius, J.D., Baker, L.M., Cooley, S., Scott, S., Cagle, L.M., Phillips, S., and Paul, R.H. (2016). Regional age differences in gray matter diffusivity among healthy older adults. Brain Imaging Behav 10; 203-211. doi: 10.1007/s11682-015-9383-7

174. Salois, G., and Smith, J.S. (2016). Housing Complexity Alters GFAPImmunoreactive Astrocyte Morphology in the Rat Dentate Gyrus. Neural Plast 2016; 3928726. doi: 10.1155/2016/3928726

175. Sampedro-Piquero, P., De Bartolo, P., Petrosini, L., Zancada-Menendez, C., Arias, J.L., and Begega, A. (2014). Astrocytic plasticity as a possible mediator of the cognitive improvements after environmental enrichment in aged rats. Neurobiology of learning and memory 114; 16-25. doi: 10.1016/j.nlm.2014.04.002

176. Schousboe, A., Scafidi, S., Bak, L.K., Waagepetersen, H.S., and McKenna, M.C. (2014). Glutamate metabolism in the brain focusing on astrocytes. $A d v$ Neurobiol 11; 13-30. doi: 10.1007/978-3-319-08894-5_2

177. Schousboe, A., and Waagepetersen, H.S. (2007). GABA: homeostatic and pharmacological aspects. Prog Brain Res 160; 9-19. doi: 10.1016/S0079-

6123(06)60002-2

178. Seifert, G., Henneberger, C., and Steinhauser, C. (2018). Diversity of astrocyte potassium channels: An update. Brain Res Bull 136; 26-36. doi:

10.1016/j.brainresbull.2016.12.002

179. Semyanov, A. (2019). Spatiotemporal pattern of calcium activity in astrocytic network. Cell Calcium 78; 15-25. doi: 10.1016/j.ceca.2018.12.007

180. Siemsen, B.M., Reichel, C.M., Leong, K.C., Garcia-Keller, C., Gipson, C.D., Spencer, S., McFaddin, J.A., Hooker, K.N., Kalivas, P.W., and Scofield, M.D. (2019). Effects of Methamphetamine Self-Administration and Extinction on Astrocyte Structure and Function in the Nucleus Accumbens Core. Neuroscience 406; 528-541. doi: 10.1016/j.neuroscience.2019.03.040

181. Sofroniew, M.V. (2009). Molecular dissection of reactive astrogliosis and glial scar formation. Trends Neurosci 32; 638-647. doi: 10.1016/j.tins.2009.08.002

182. Sofroniew, M.V. (2014). Astrogliosis. Cold Spring Harb Perspect Biol 7; a020420. doi: 10.1101/cshperspect.a020420

183. Sonntag, W.E., Deak, F., Ashpole, N., Toth, P., Csiszar, A., Freeman, W., and Ungvari, Z. (2013). Insulin-like growth factor-1 in CNS and cerebrovascular aging. Front Aging Neurosci 5; 27. doi: 10.3389/fnagi.2013.00027

184. Soreq, L., Consortium, U.K.B.E., North American Brain Expression, C., Rose, J., Soreq, E., Hardy, J., Trabzuni, D., Cookson, M.R., Smith, C., Ryten, M., Patani, R., and Ule, J. (2017). Major Shifts in Glial Regional Identity Are a Transcriptional Hallmark of Human Brain Aging. Cell Rep 18; 557-570. doi:

10.1016/j.celrep.2016.12.011 
185. Souza, D.G., Bellaver, B., Souza, D.O., and Quincozes-Santos, A. (2013). Characterization of adult rat astrocyte cultures. PLoS One 8; e60282. doi: 10.1371/journal.pone.0060282

186. Stern, Y. (2009). Cognitive reserve. Neuropsychologia 47; 2015-2028. doi: 10.1016/j.neuropsychologia.2009.03.004

187. Streit, W.J., Braak, H., Xue, Q.S., and Bechmann, I. (2009). Dystrophic (senescent) rather than activated microglial cells are associated with tau pathology and likely precede neurodegeneration in Alzheimer's disease. Acta Neuropathol 118; 475-485. doi: 10.1007/s00401-009-0556-6

188. Streit, W.J., Khoshbouei, H., and Bechmann, I. (2020). Dystrophic microglia in late-onset Alzheimer's disease. Glia 68; 845-854. doi: 10.1002/glia.23782

189. Streit, W.J., Sammons, N.W., Kuhns, A.J., and Sparks, D.L. (2004). Dystrophic microglia in the aging human brain. Glia 45; 208-212. doi: 10.1002/glia.10319

190. Streit, W.J., Xue, Q.S., Tischer, J., and Bechmann, I. (2014). Microglial pathology. Acta Neuropathol Commun 2; 142. doi: 10.1186/s40478-014-0142-6 191. Strolin Benedetti, M., and Dostert, P. (1989). Monoamine oxidase, brain ageing and degenerative diseases. Biochem Pharmacol 38; 555-561. doi:

10.1016/0006-2952(89)90198-6

192. Sun, N., Youle, R.J., and Finkel, T. (2016). The Mitochondrial Basis of Aging. Mol Cell 61; 654-666. doi: 10.1016/j.molcel.2016.01.028

193. Sweeney, M.D., Zhao, Z., Montagne, A., Nelson, A.R., and Zlokovic, B.V. (2019). Blood-Brain Barrier: From Physiology to Disease and Back. Physiol Rev 99; 21-78. doi: 10.1152/physrev.00050.2017

194. Sykova, E., and Nicholson, C. (2008). Diffusion in brain extracellular space. Physiol Rev 88; 1277-1340. doi: 10.1152/physrev.00027.2007

195. Tachibana, M., Mohri, I., Hirata, I., Kuwada, A., Kimura-Ohba, S., KagitaniShimono, K., Fushimi, H., Inoue, T., Shiomi, M., Kakuta, Y., Takeuchi, M., Murayama, S., Nakayama, M., Ozono, K., and Taniike, M. (2019). Clasmatodendrosis is associated with dendritic spines and does not represent autophagic astrocyte death in influenza-associated encephalopathy. Brain Dev 41; 85-95. doi:

10.1016/j.braindev.2018.07.008

196. Tanaka, M., Shih, P.Y., Gomi, H., Yoshida, T., Nakai, J., Ando, R., Furuichi, T., Mikoshiba, K., Semyanov, A., and Itohara, S. (2013). Astrocytic $\mathrm{Ca}^{2+}$ signals are required for the functional integrity of tripartite synapses. Mol Brain 6; 6. doi:

10.1186/1756-6606-6-6

197. Tarantini, S., Tran, C.H.T., Gordon, G.R., Ungvari, Z., and Csiszar, A. (2017). Impaired neurovascular coupling in aging and Alzheimer's disease: Contribution of astrocyte dysfunction and endothelial impairment to cognitive decline. Exp Gerontol 94; 52-58. doi: 10.1016/j.exger.2016.11.004

198. Toth, P., Tarantini, S., Ashpole, N.M., Tucsek, Z., Milne, G.L., ValcarcelAres, N.M., Menyhart, A., Farkas, E., Sonntag, W.E., Csiszar, A., and Ungvari, Z. (2015). IGF-1 deficiency impairs neurovascular coupling in mice: implications for cerebromicrovascular aging. Aging Cell 14; 1034-1044. doi: 10.1111/acel.12372 199. Vanzulli, I., Papanikolaou, M., De-La-Rocha, I.C., Pieropan, F., Rivera, A.D., Gomez-Nicola, D., Verkhratsky, A., Rodriguez, J.J., and Butt, A.M. (2020).

Disruption of oligodendrocyte progenitor cells is an early sign of pathology in the triple transgenic mouse model of Alzheimer's disease. Neurobiol Aging 94; 130-139. doi: 10.1016/j.neurobiolaging.2020.05.016 
200. Vaughan, D.W., and Peters, A. (1974). Neuroglial cells in the cerebral cortex of rats from young adulthood to old age: An electron microscope study J. Neurocytol. 3; 405-429. doi:

201. Verkhratsky, A., and Butt, A.M. (2013). Glial Physiology and Pathophysiology. (Chichester: Wiley-Blackwell).

202. Verkhratsky, A., Marutle, A., Rodriguez-Arellano, J.J., and Nordberg, A. (2015). Glial Asthenia and Functional Paralysis: A New Perspective on Neurodegeneration and Alzheimer's Disease. Neuroscientist 21; 552-568. doi: $10.1177 / 1073858414547132$

203. Verkhratsky, A., and Nedergaard, M. (2014). Astroglial cradle in the life of the synapse. Philos Trans R Soc Lond B Biol Sci 369; 20130595. doi:

10.1098/rstb.2013.0595

204. Verkhratsky, A., and Nedergaard, M. (2018). Physiology of Astroglia. Physiol Rev 98; 239-389. doi: 10.1152/physrev.00042.2016

205. Verkhratsky, A., Olabarria, M., Noristani, H.N., Yeh, C.Y., and Rodriguez, J.J. (2010). Astrocytes in Alzheimer's disease. Neurotherapeutics 7; 399-412. doi:

10.1016/j.nurt.2010.05.017

206. Verkhratsky, A., Rodrigues, J.J., Pivoriunas, A., Zorec, R., and Semyanov, A. (2019). Astroglial atrophy in Alzheimer's disease. Pflugers Arch 471; 1247-1261. doi: 10.1007/s00424-019-02310-2

207. Verkhratsky, A., and Rose, C.R. (2020). $\mathrm{Na}^{+}$-dependent transporters: The backbone of astroglial homeostatic function. Cell Calcium 85; 102136. doi:

$10.1016 /$ j.ceca. 2019.102136

208. Verkhratsky, A., and Steinhauser, C. (2000). Ion channels in glial cells. Brain Res Brain Res Rev 32; 380-412. doi: 10.1016/s0165-0173(99)00093-4

209. Verkhratsky, A., Untiet, V., and Rose, C.R. (2020). Ionic signalling in astroglia beyond calcium. $J$ Physiol 598; 1655-1670. doi: 10.1113/JP277478

210. Verkhratsky, A., Zorec, R., and Parpura, V. (2017). Stratification of astrocytes in healthy and diseased brain. Brain Pathol 27; 629-644. doi: 10.1111/bpa.12537

211. Vilchez, D., Saez, I., and Dillin, A. (2014). The role of protein clearance mechanisms in organismal ageing and age-related diseases. Nat Commun 5; 5659. doi: $10.1038 /$ ncomms6659

212. Viola, G.G., Rodrigues, L., Americo, J.C., Hansel, G., Vargas, R.S., Biasibetti, R., Swarowsky, A., Goncalves, C.A., Xavier, L.L., Achaval, M., Souza, D.O., and Amaral, O.B. (2009). Morphological changes in hippocampal astrocytes induced by environmental enrichment in mice. Brain Res 1274; 47-54. doi:

10.1016/j.brainres.2009.04.007

213. Walhovd, K.B., Johansen-Berg, H., and Karadottir, R.T. (2014). Unraveling the secrets of white matter - Bridging the gap between cellular, animal and human imaging studies. Neuroscience 276C; 2-13. doi: 10.1016/j.neuroscience.2014.06.058 214. Wardlaw, J.M., Benveniste, H., Nedergaard, M., Zlokovic, B.V., Mestre, H., Lee, H., Doubal, F.N., Brown, R., Ramirez, J., MacIntosh, B.J., Tannenbaum, A., Ballerini, L., Rungta, R.L., Boido, D., Sweeney, M., Montagne, A., Charpak, S., Joutel, A., Smith, K.J., Black, S.E., and colleagues from the Fondation Leducq Transatlantic Network of Excellence on the Role of the Perivascular Space in Cerebral Small Vessel, D. (2020). Perivascular spaces in the brain: anatomy, physiology and pathology. Nat Rev Neurol 16; 137-153. doi: 10.1038/s41582-0200312-z 
215. Watts, M.E., Pocock, R., and Claudianos, C. (2018). Brain Energy and Oxygen Metabolism: Emerging Role in Normal Function and Disease. Front Mol Neurosci 11; 216. doi: 10.3389/fnmol.2018.00216

216. Weismann, A. (1889). Collected Essays upon Heredity and Kindred Biological Problems. (Oxford: Clarendon).

217. Westlund, K.N., Denney, R.M., Rose, R.M., and Abell, C.W. (1988). Localization of distinct monoamine oxidase A and monoamine oxidase B cell populations in human brainstem. Neuroscience 25; 439-456. doi: 10.1016/03064522(88)90250-3

218. Wheeler, M.A., Clark, I.C., Tjon, E.C., Li, Z., Zandee, S.E.J., Couturier, C.P., Watson, B.R., Scalisi, G., Alkwai, S., Rothhammer, V., Rotem, A., Heyman, J.A., Thaploo, S., Sanmarco, L.M., Ragoussis, J., Weitz, D.A., Petrecca, K., Moffitt, J.R., Becher, B., Antel, J.P., Prat, A., and Quintana, F.J. (2020). MAFG-driven astrocytes promote CNS inflammation. Nature 578; 593-599. doi: 10.1038/s41586-020-1999-0 219. Wilhelmsson, U., Bushong, E.A., Price, D.L., Smarr, B.L., Phung, V., Terada, M., Ellisman, M.H., and Pekny, M. (2006). Redefining the concept of reactive astrocytes as cells that remain within their unique domains upon reaction to injury. Proc Natl Acad Sci U S A 103; 17513-17518. doi: 10.1073/pnas.0602841103 220. Wu, Y., Zhang, A.Q., and Yew, D.T. (2005). Age related changes of various markers of astrocytes in senescence-accelerated mice hippocampus. Neurochem Int 46; 565-574. doi: 10.1016/j.neuint.2005.01.002

221. Wu, Y.W., Gordleeva, S., Tang, X., Shih, P.Y., Dembitskaya, Y., and Semyanov, A. (2019). Morphological profile determines the frequency of spontaneous calcium events in astrocytic processes. Glia 67; 246-262. doi: 10.1002/glia.23537 222. Wu, Z., Guo, Z., Gearing, M., and Chen, G. (2014). Tonic inhibition in dentate gyrus impairs long-term potentiation and memory in an Alzheimer's [corrected] disease model. Nat Commun 5; 4159. doi: 10.1038/ncomms5159

223. Ximerakis, M., Lipnick, S.L., Innes, B.T., Simmons, S.K., Adiconis, X., Dionne, D., Mayweather, B.A., Nguyen, L., Niziolek, Z., Ozek, C., Butty, V.L., Isserlin, R., Buchanan, S.M., Levine, S.S., Regev, A., Bader, G.D., Levin, J.Z., and Rubin, L.L. (2019). Single-cell transcriptomic profiling of the aging mouse brain. Nat Neurosci 22; 1696-1708. doi: 10.1038/s41593-019-0491-3

224. Zamanian, J.L., Xu, L., Foo, L.C., Nouri, N., Zhou, L., Giffard, R.G., and Barres, B.A. (2012). Genomic analysis of reactive astrogliosis. J Neurosci 32; 63916410. doi: 10.1523/JNEUROSCI.6221-11.2012

225. Zonta, M., Angulo, M.C., Gobbo, S., Rosengarten, B., Hossmann, K.A., Pozzan, T., and Carmignoto, G. (2003). Neuron-to-astrocyte signaling is central to the dynamic control of brain microcirculation. Nat Neurosci 6; 43-50. doi: 10.1038/nn980 nn980 [pii]

226. Zorec, R., Parpura, V., and Verkhratsky, A. (2018). Preventing neurodegeneration by adrenergic astroglial excitation. FEBS J. doi: $10.1111 /$ febs. 14456 


\section{Figure legends}

Figure 1. Classification of astrogliopathology (see text for further explanations).

Figure 2. Reconstructions of hippocampal protoplasmic astrocytes from young, adult and old mice (own observations).

Figure 3. Age-dependent remodelling of astroglial profiles in different brain areas.

Confocal images showing glial fibrillary acidic protein-GFAP (A to F), s100B ( $\mathrm{G}$ to L) and glutamine synthetase-GS (M to R) immunolabelled astrocytes in the dentate gyrus and CA1 hippocampal areas as well as in the entorhinal cortex of mice at 3 and 24 months. Modified from [166].

Figure 4. Age-dependent shrinkage of astroglial peripheral processes opens diffusional channels in the neuropil thus providing a mechanistic explanation of an increased diffusivity of the grey matter observed in old humans by diffusion tensor imaging.

Figure 5. Ageing affects the density of plasmalemmal glutamate transporters and ionotropic receptor-mediated currents in acutely isolated single cortical astrocytes.

A. Representative whole-cell currents elicited in the acutely isolated astrocytes by application of $100 \mu \mathrm{M}$ glutamate (left column), $10 \mu \mathrm{M}$ NMDA (middle column) and $10 \mu \mathrm{M}$ ATP/ $\alpha \beta$ meATP (a potent and stable agonist at P2 $\mathrm{X}_{1}, \mathrm{P} 2 \mathrm{X}_{3}, \mathrm{P} 2 \mathrm{X}_{2 / 3}, \mathrm{P} 2 \mathrm{X}_{1 / 5}$ and $\mathrm{P} 2 \mathrm{X}_{4 / 6}$ receptors. It is also a weak partial agonist at human and mouse $\mathrm{P} 2 \mathrm{X}_{4}$ receptors, but an antagonist at the rat $\mathrm{P} 2 \mathrm{X}_{4}$ receptor; it has little or no effect at other $\mathrm{P} 2 \mathrm{X}$ and $\mathrm{P} 2 \mathrm{Y}$ receptors), at holding potential of $-80 \mathrm{mV}$. Glutamate- and NMDA-evoked currents were inhibited by $10 \mu \mathrm{M}$ D-AP5, an NMDA antagonist, and $30 \mu \mathrm{M}$ CNQX, an AMPA receptor antagonist; ATP-evoked currents were inhibited by $10 \mu \mathrm{M}$ PPADS, a selective purinergic $\mathrm{P} 2 \mathrm{X}$ antagonist.

B. The density of currents mediated by P2X, NMDA and AMPA receptors and plasmalemmal glutamate transporters (GluT) in cortical astrocytes (mean \pm SD for 9 12 cells for each age group); statistical significance of difference between average value for 1 month and corresponding values for 3 and 6 months $\mathrm{P}<0.02$ (ANOVA) for all types of currents.

Reproduced with permission from [97].

Figure 6. Loss of function in aged astrocytes. 


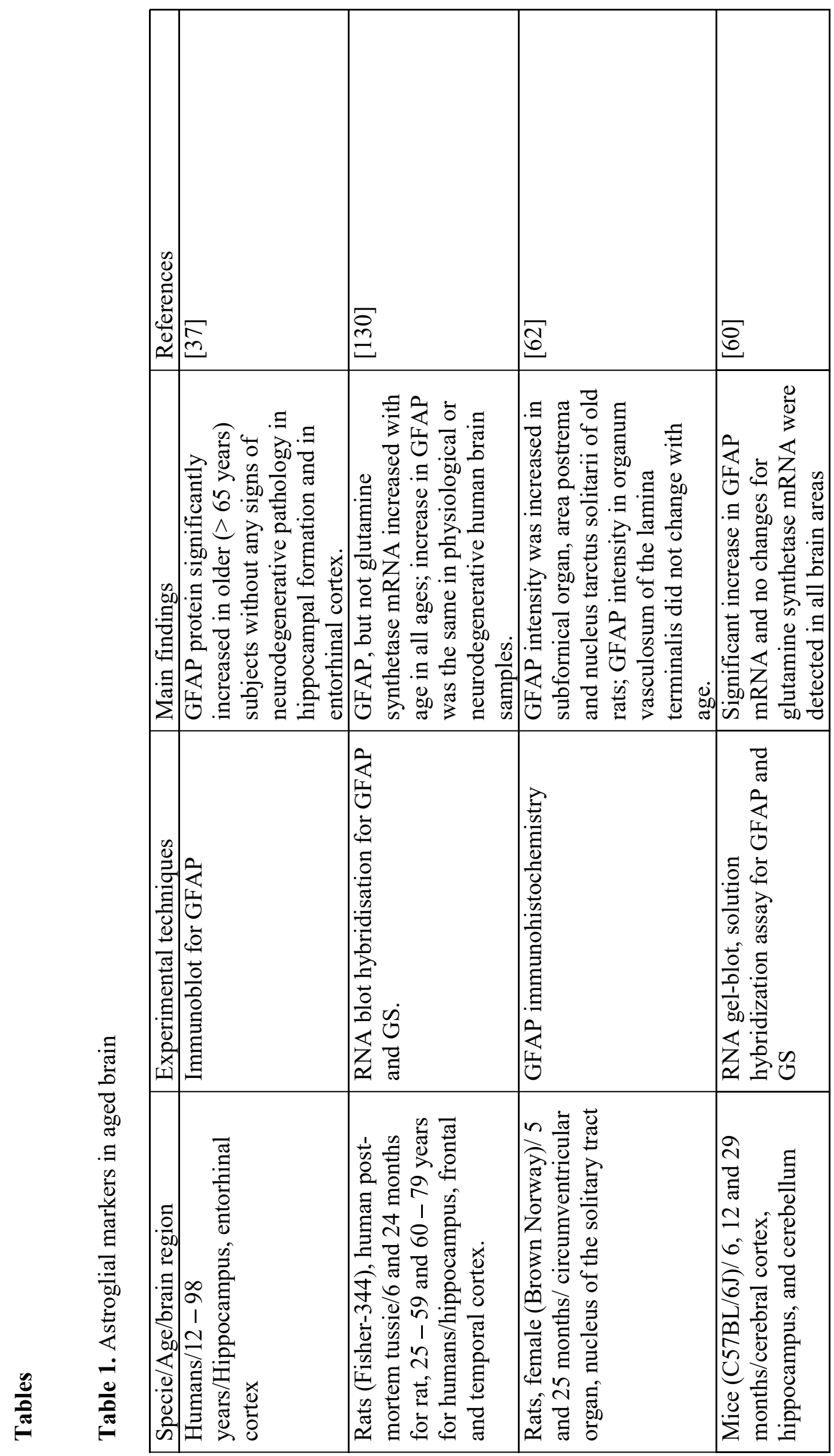


i
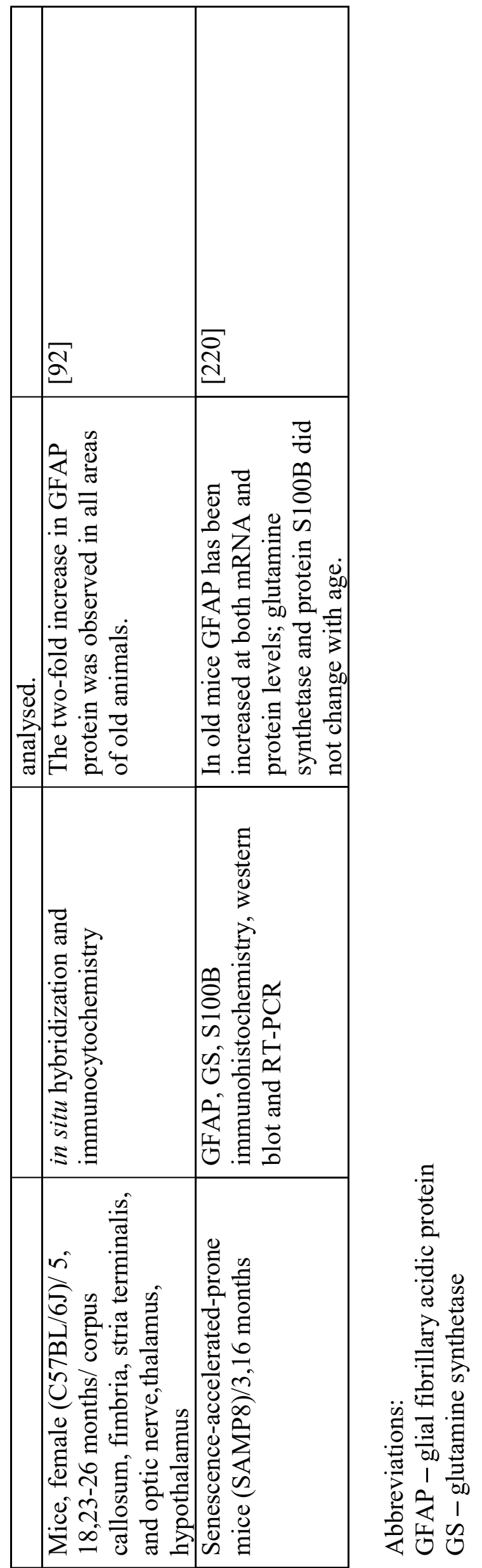
$\hat{n}$

\begin{tabular}{|c|c|c|c|c|c|}
\hline & $\begin{array}{l}\infty \\
\curvearrowleft \\
\beth\end{array}$ & $\Xi$ & $\begin{array}{l}\infty \\
i n \\
i\end{array}$ & 文 & 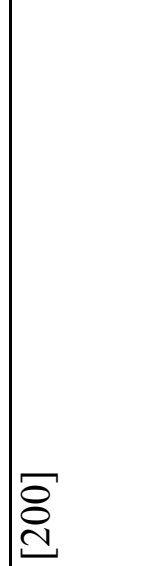 \\
\hline & 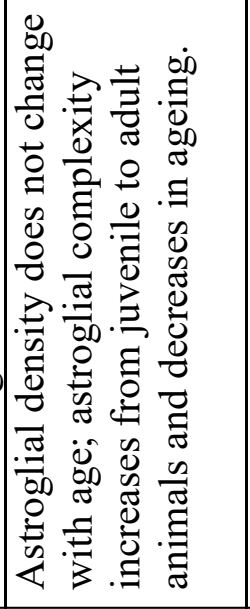 & 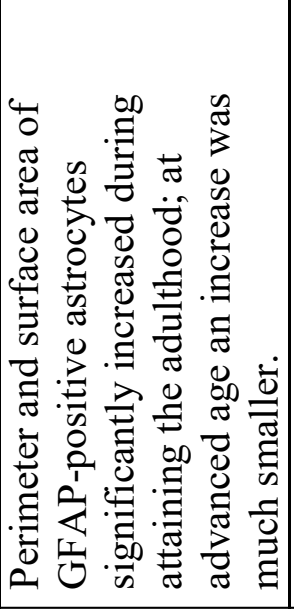 & 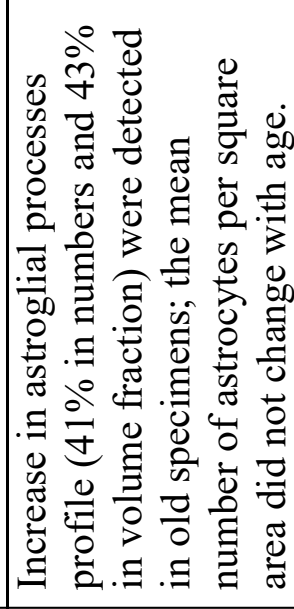 & 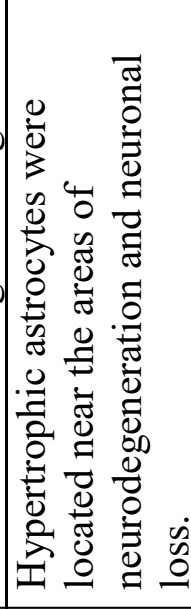 & 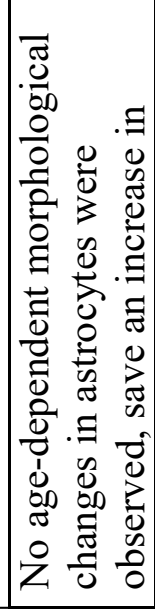 \\
\hline 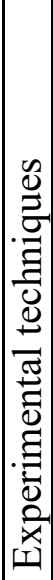 & 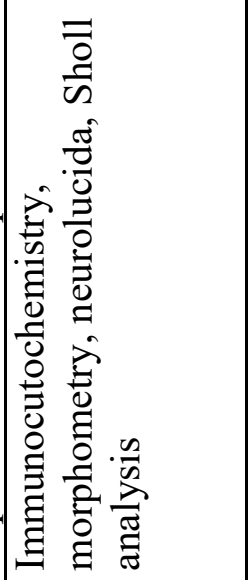 & 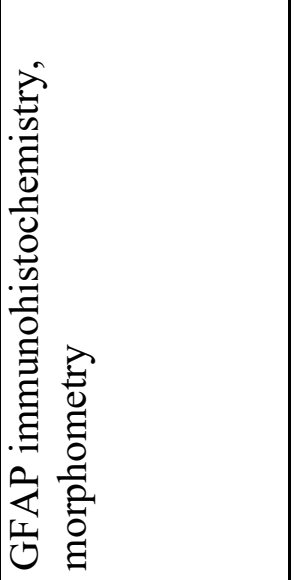 & 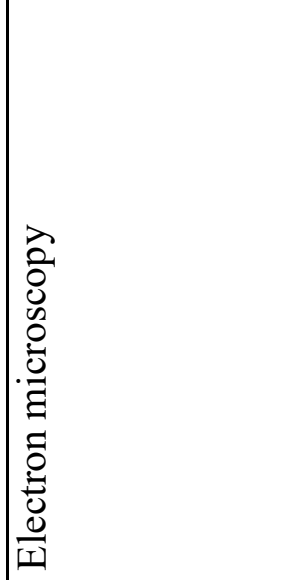 & 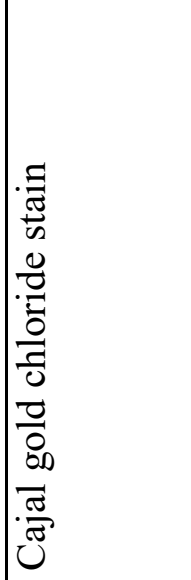 & 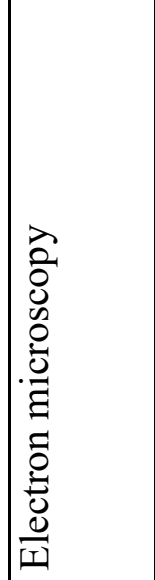 \\
\hline 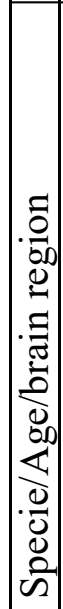 & 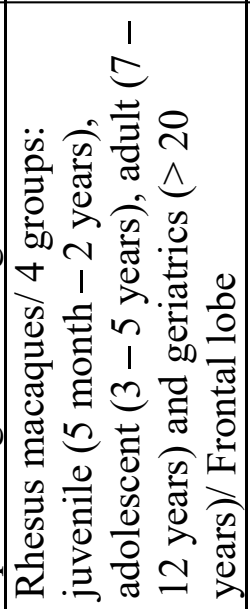 & 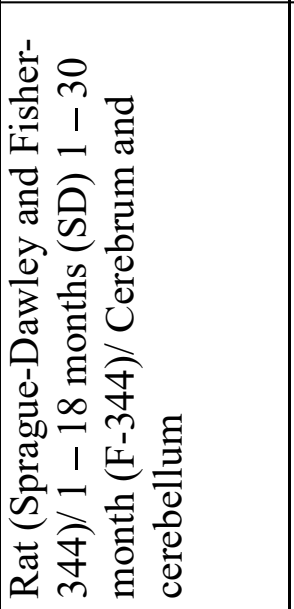 & 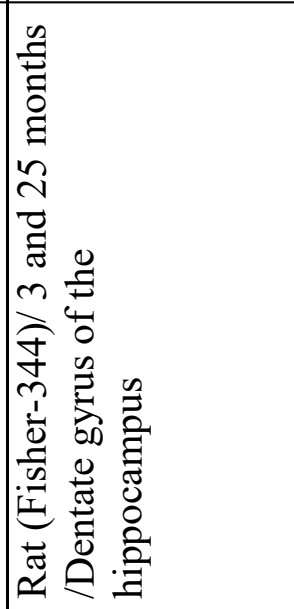 & 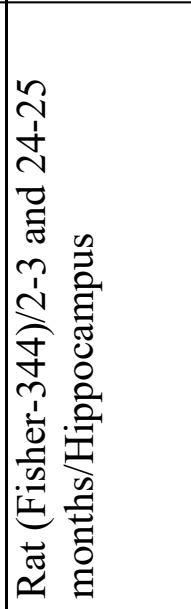 & 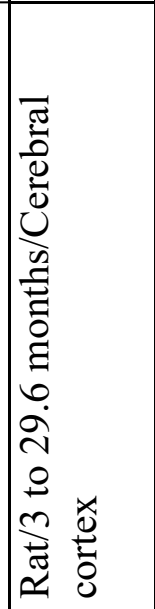 \\
\hline
\end{tabular}


$\infty$

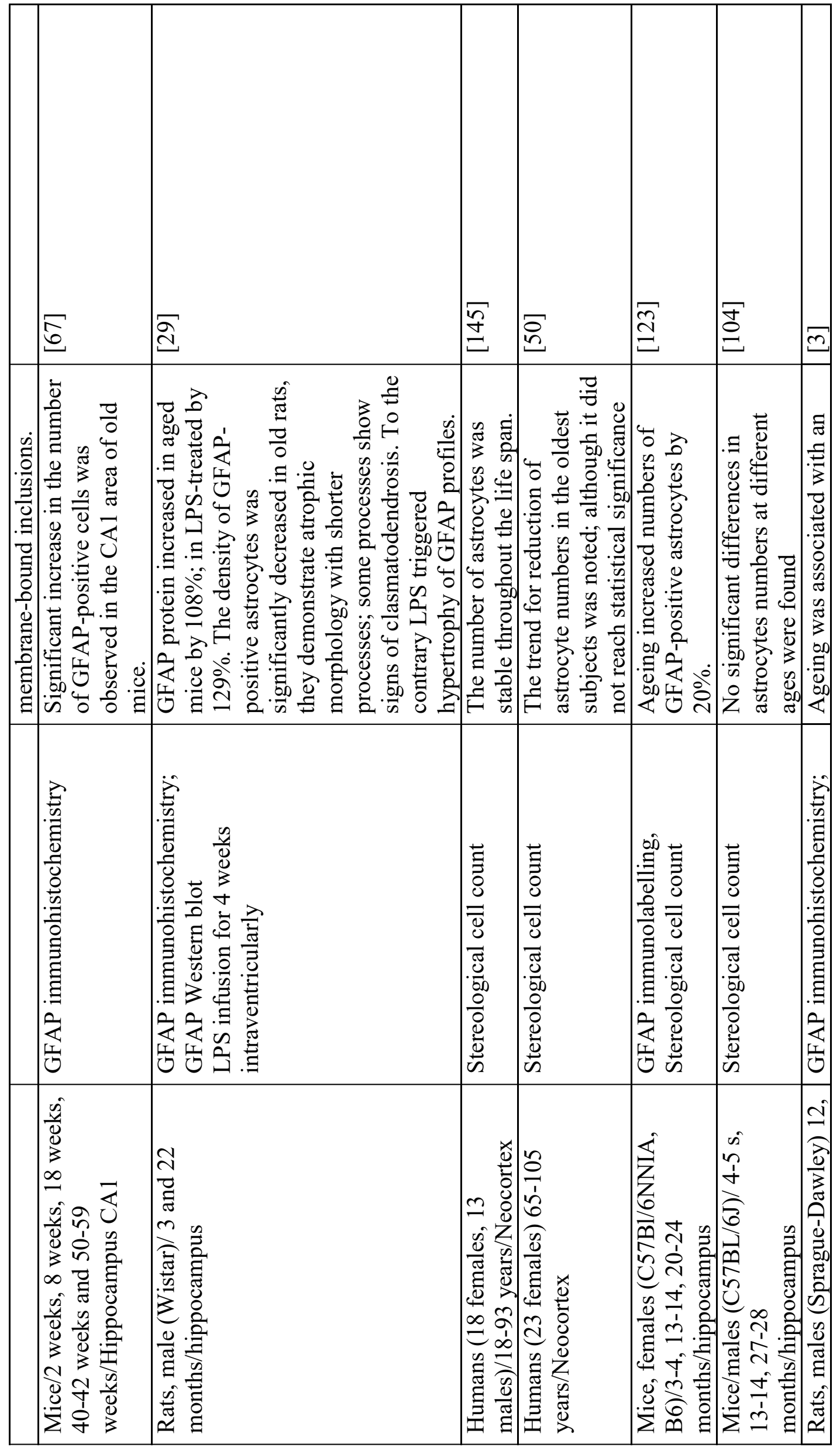


ले

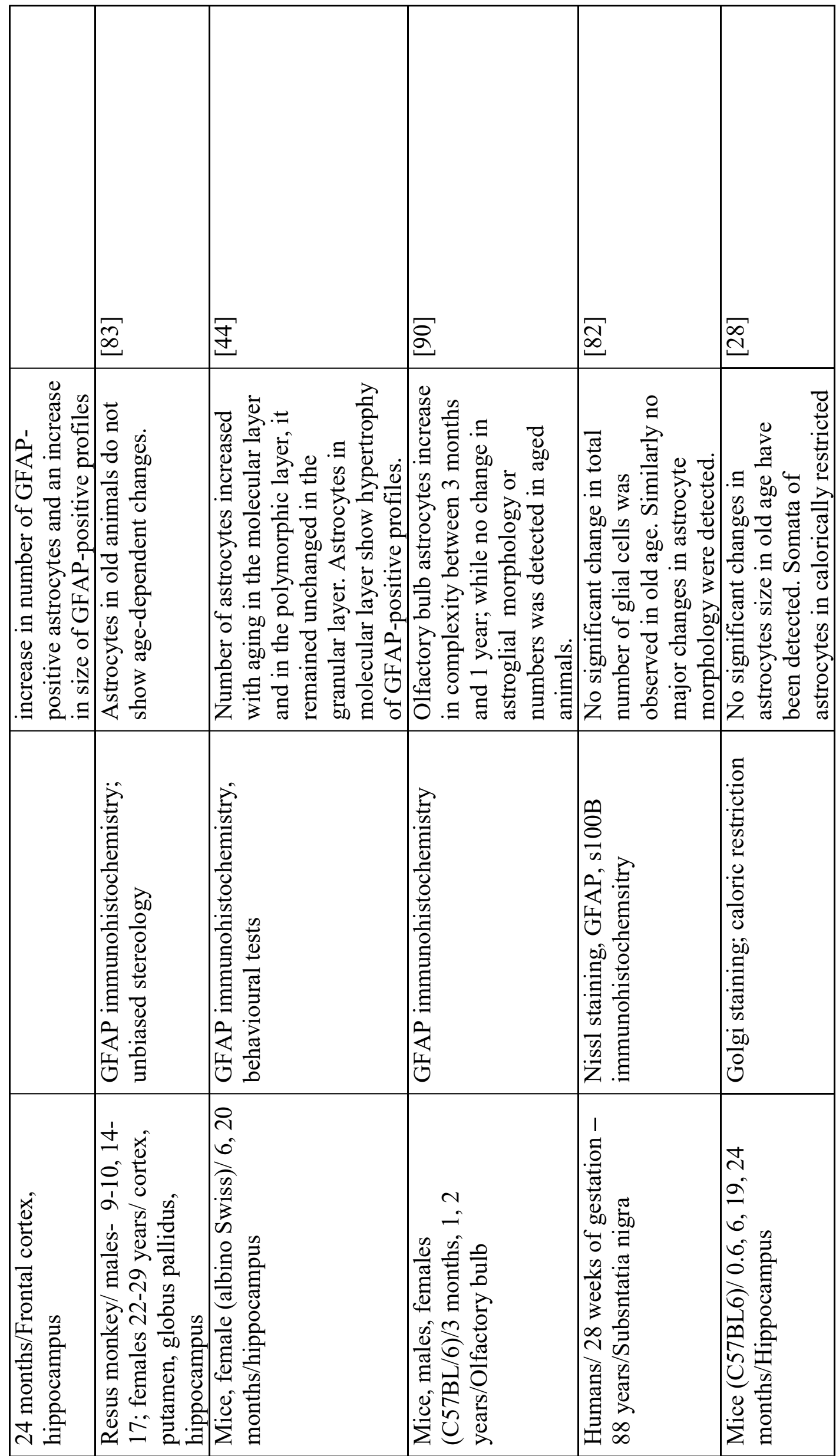




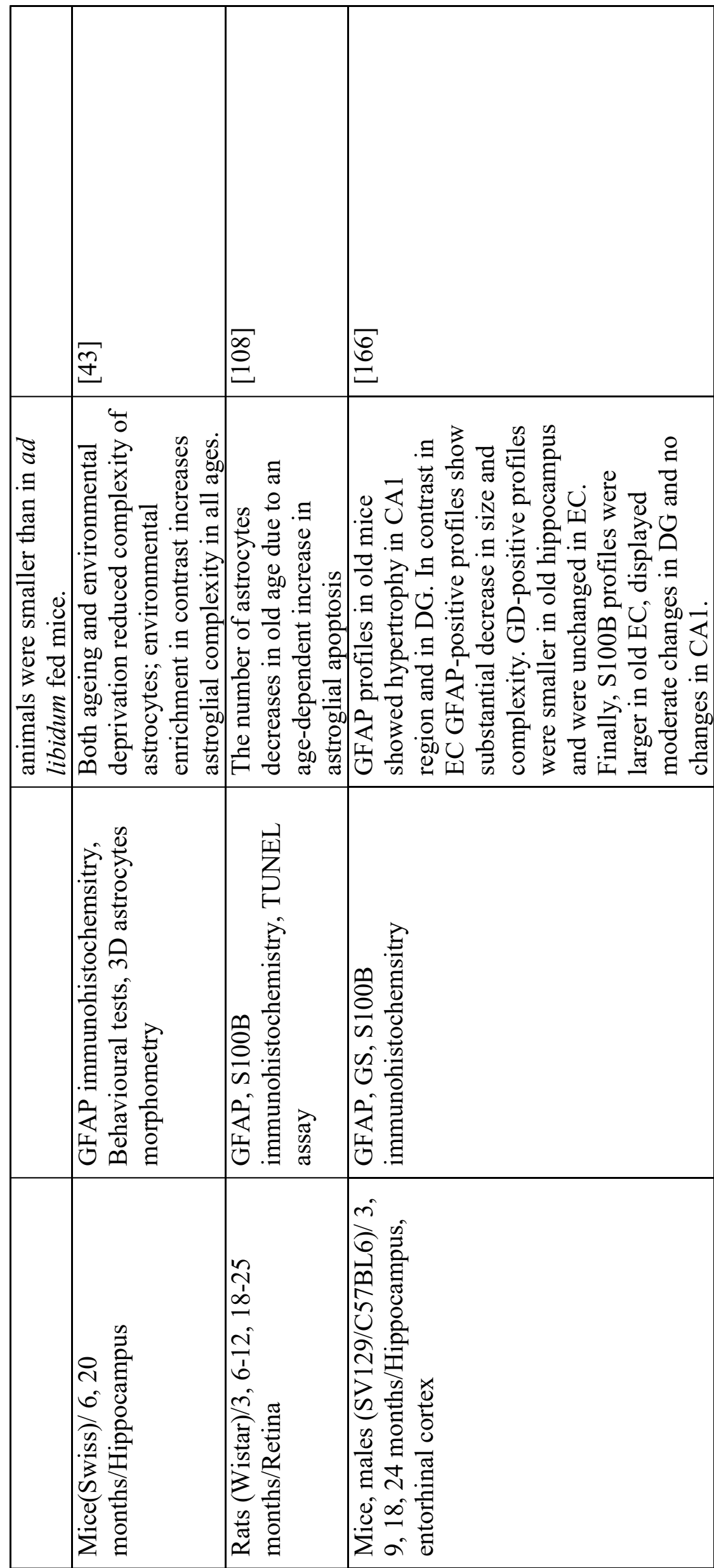




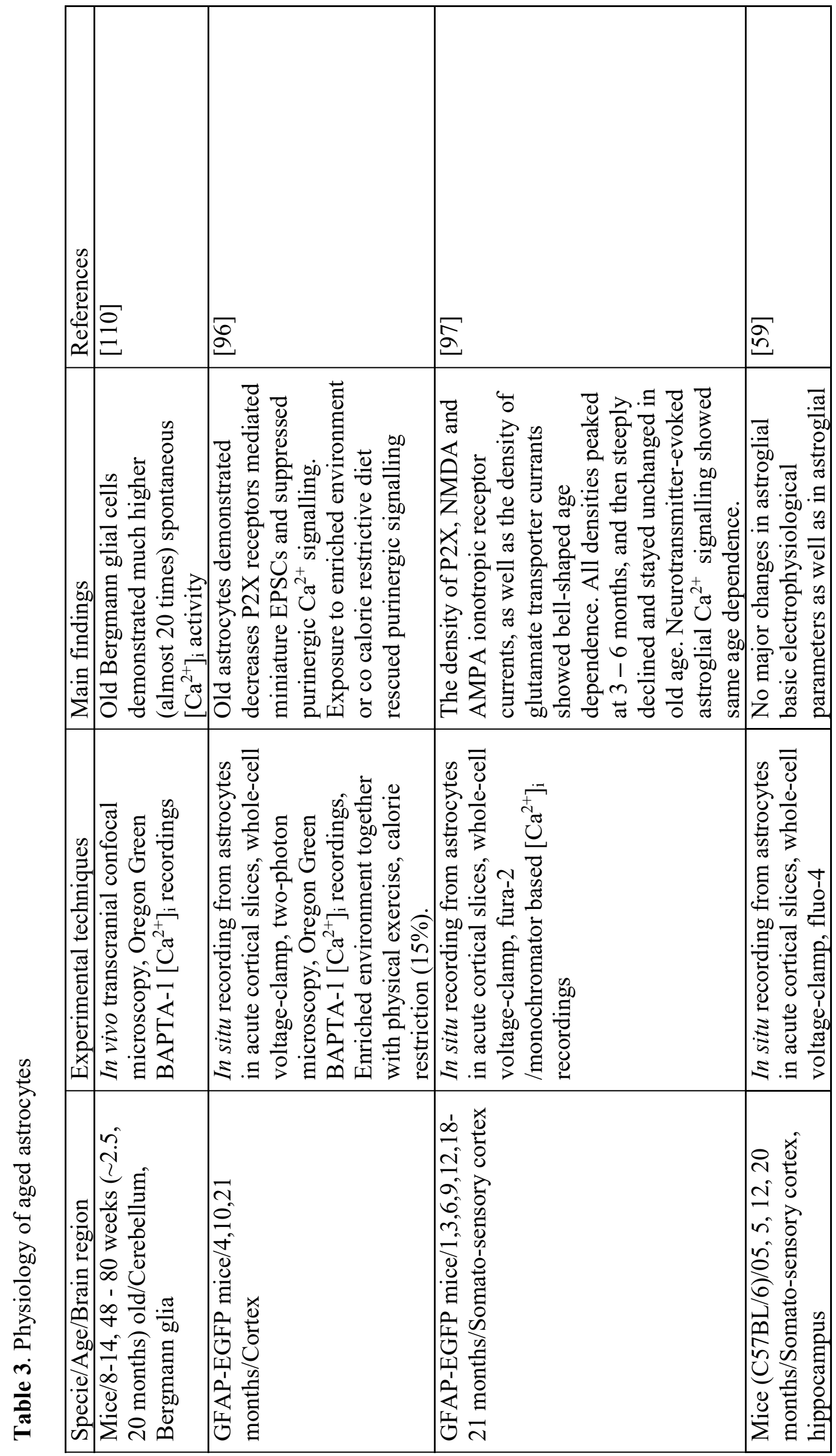




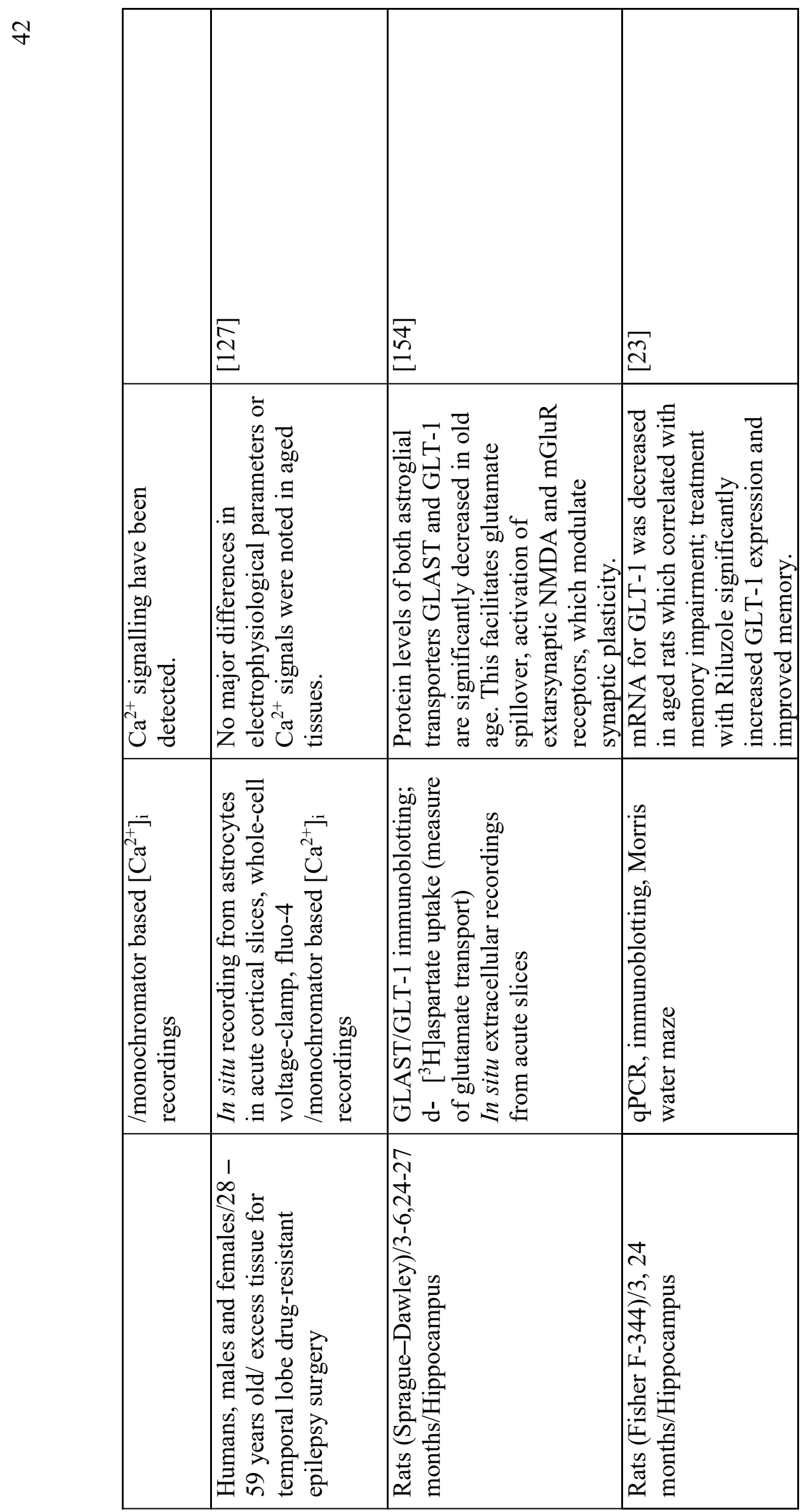




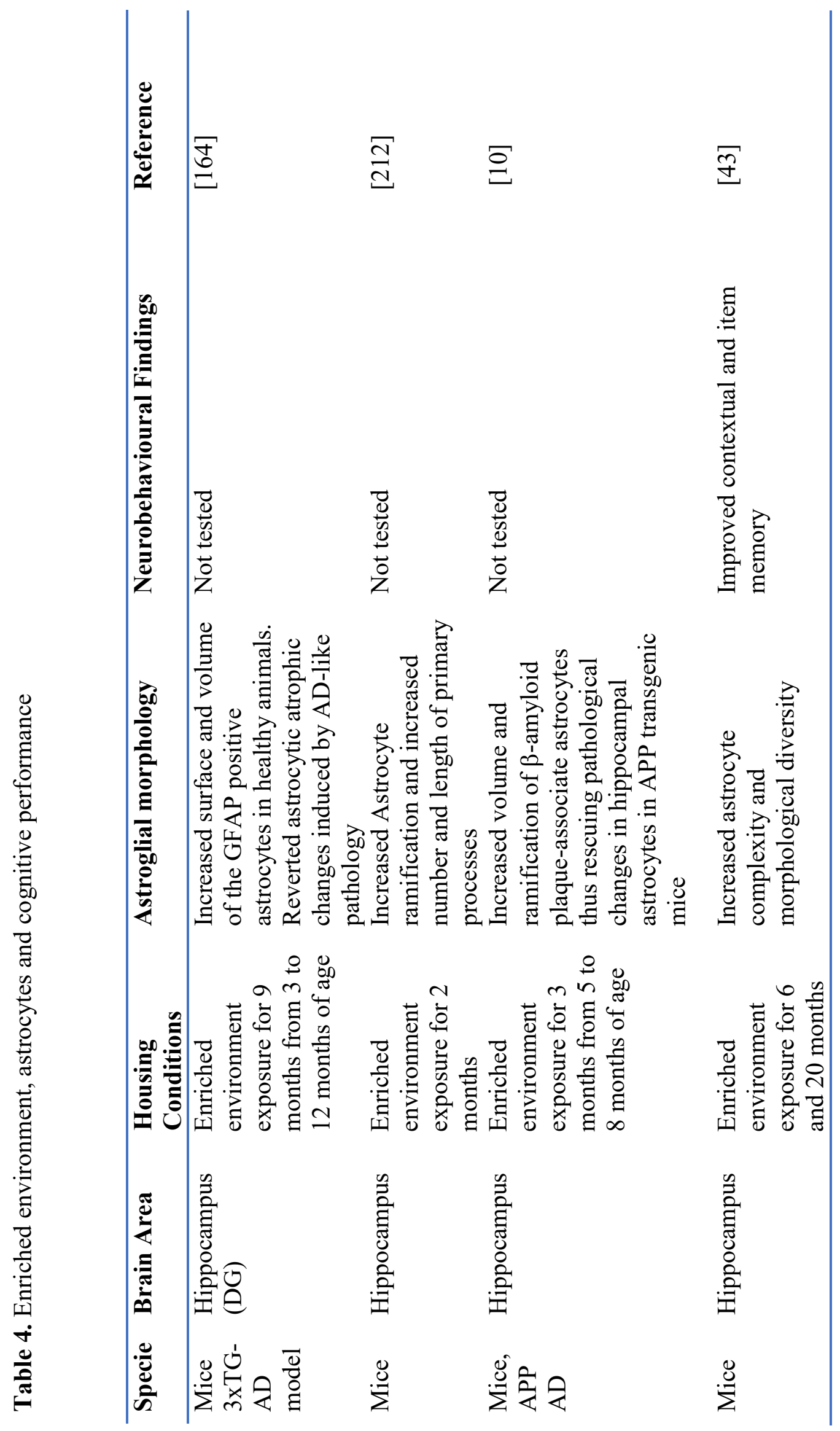




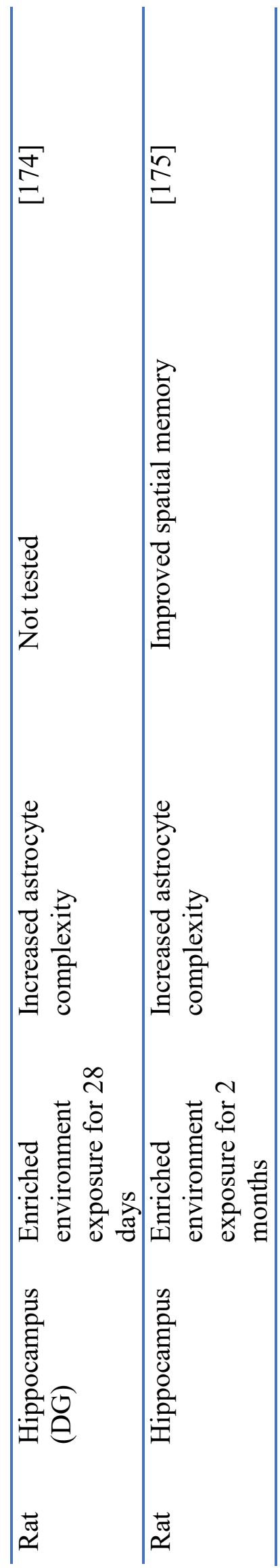

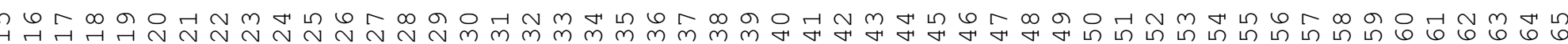




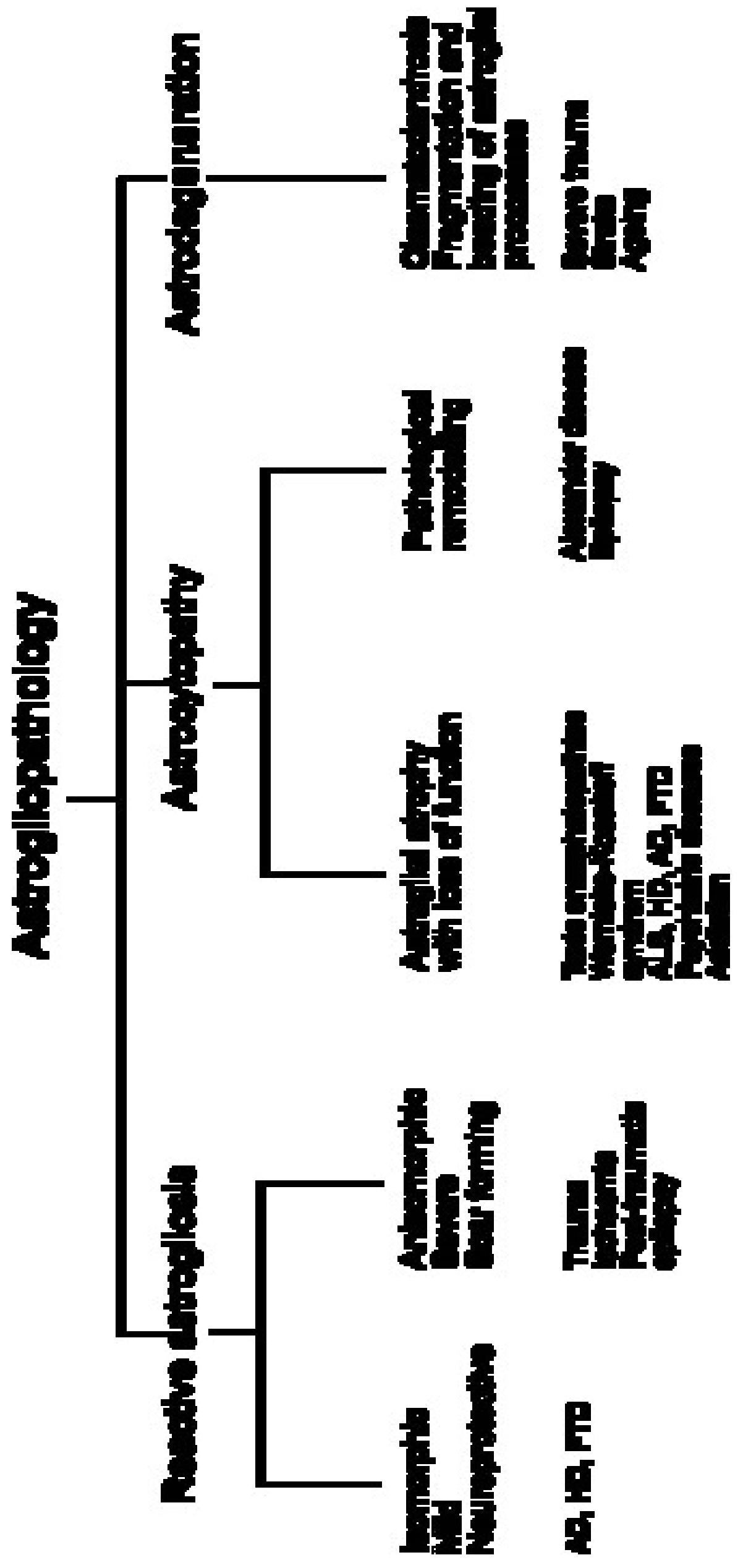




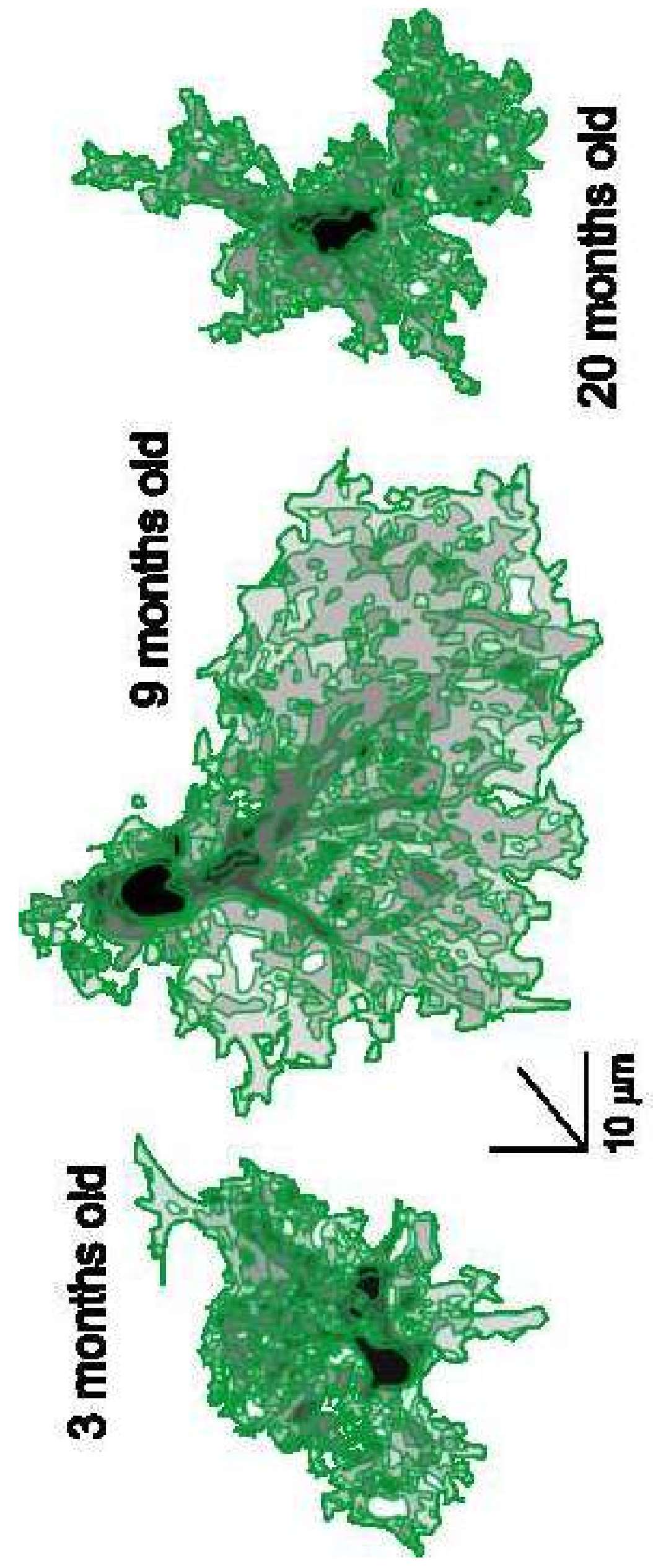

I 

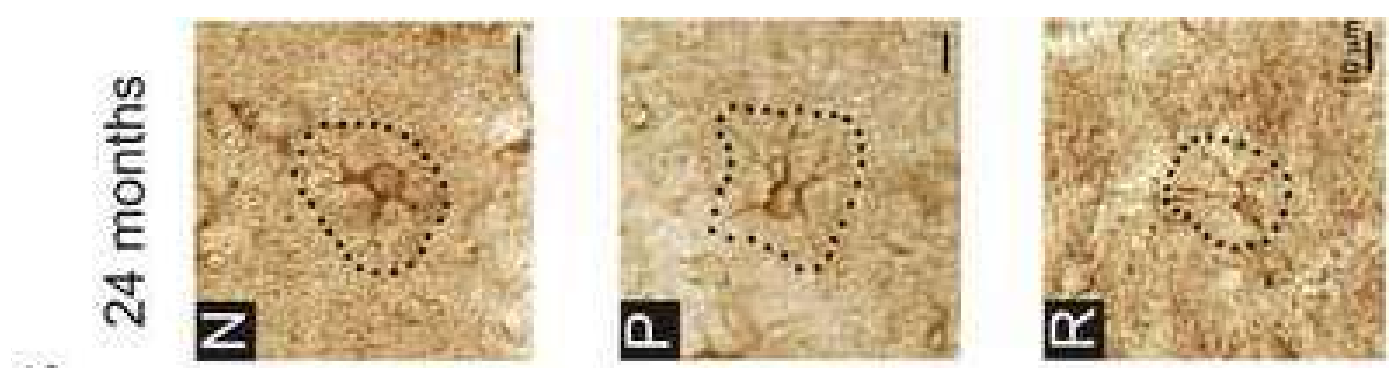

(1)
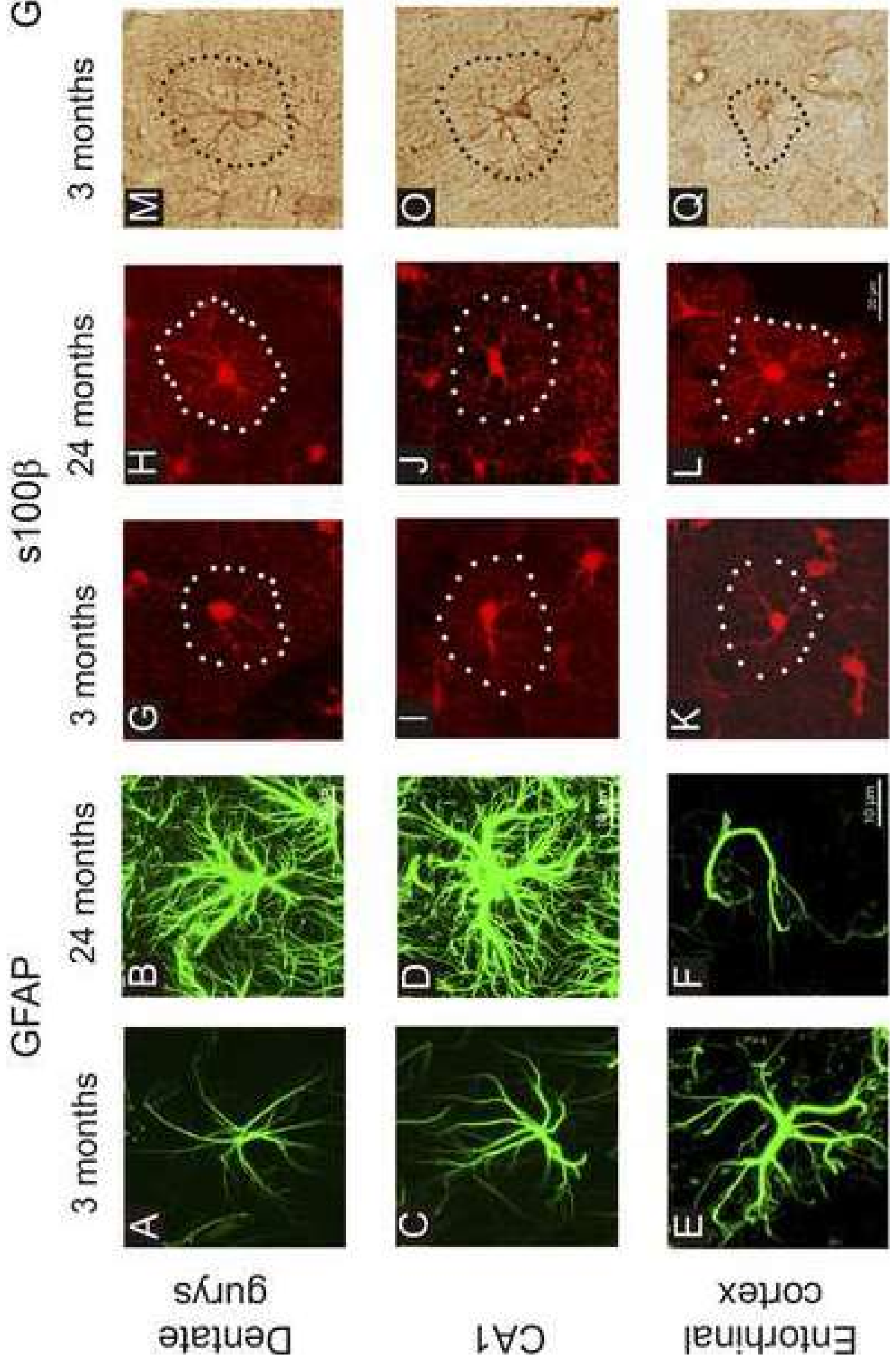

$\llcorner\forall \supset$

ןеuाчнови 


\section{Adult brain}
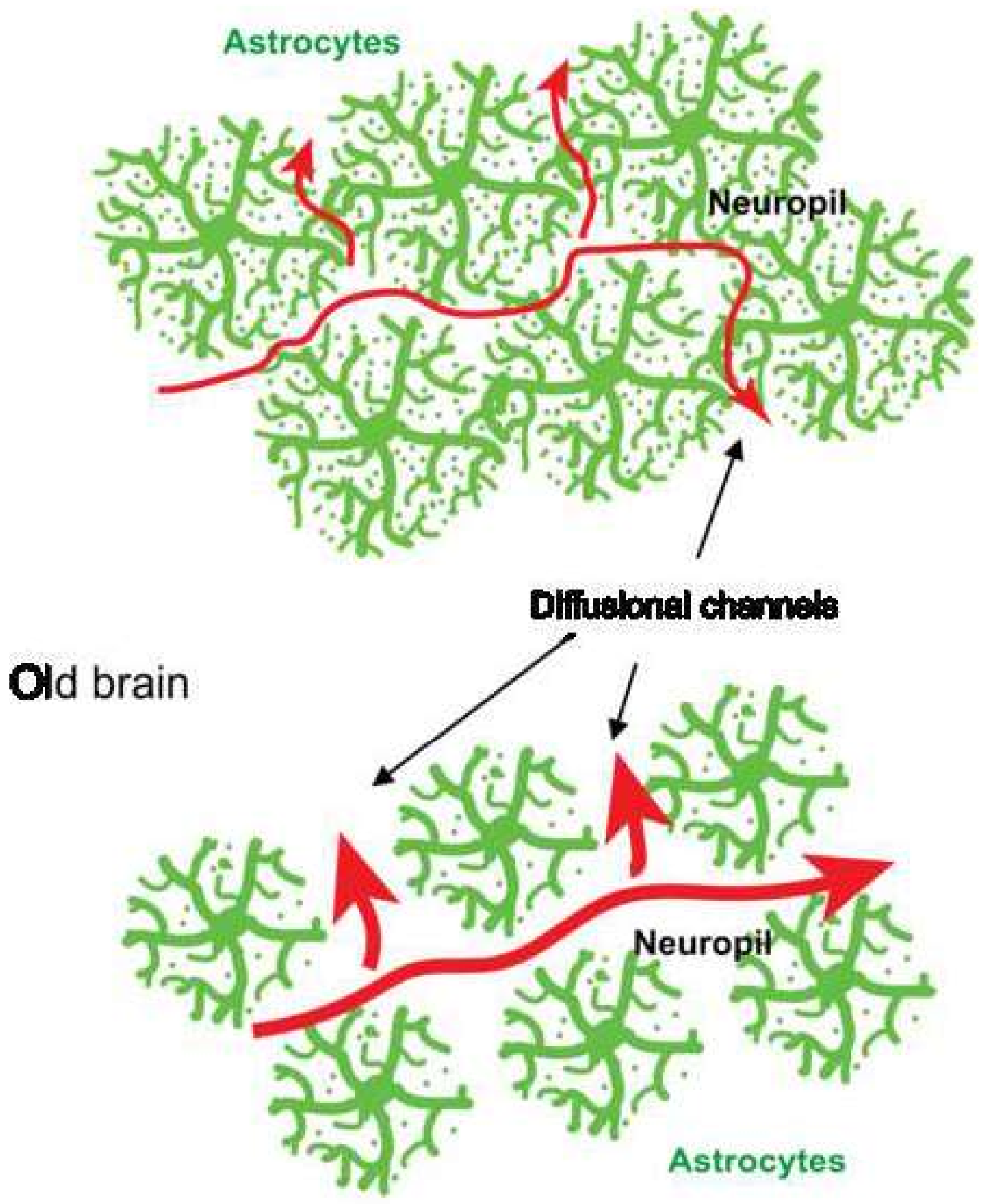

F7 4 

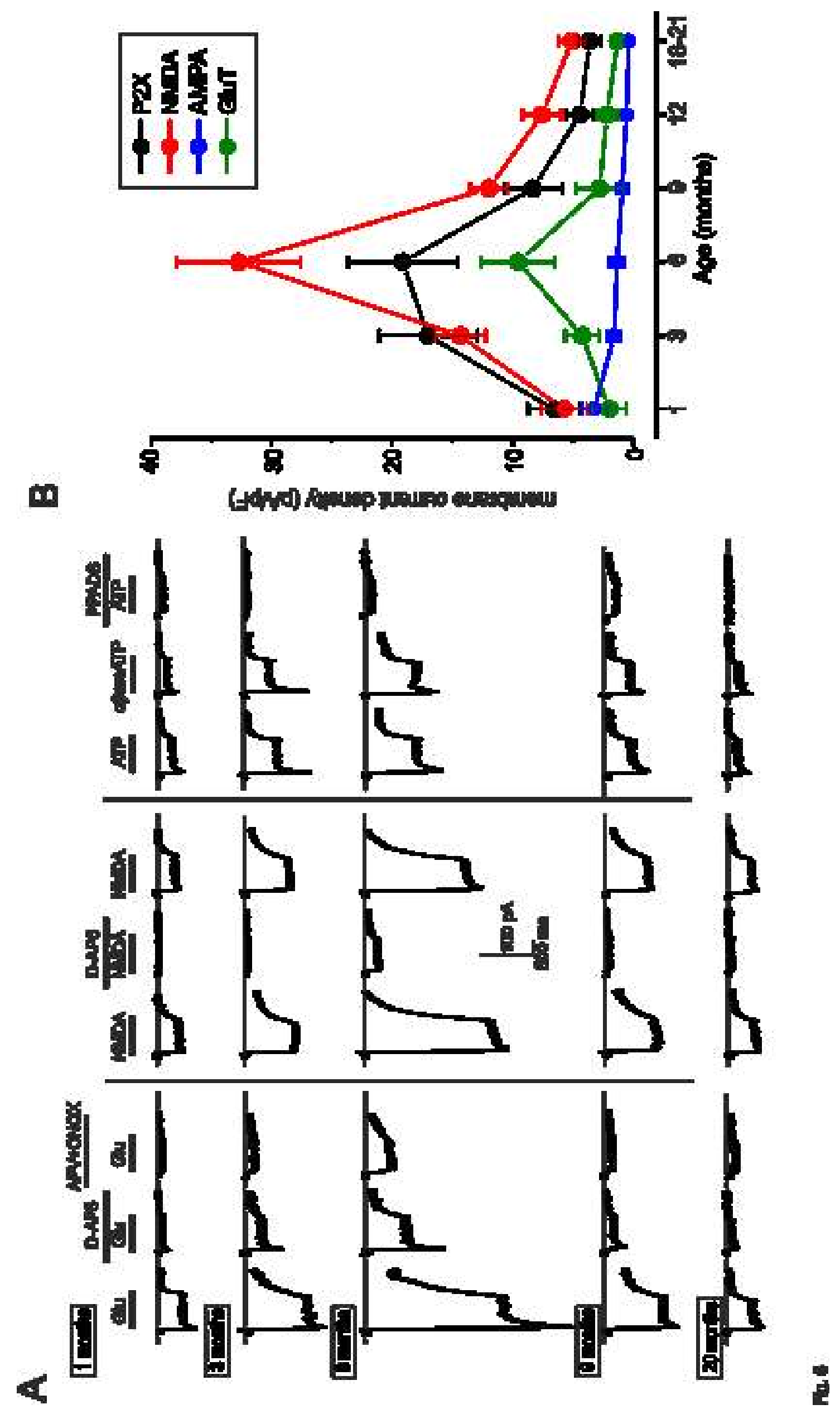

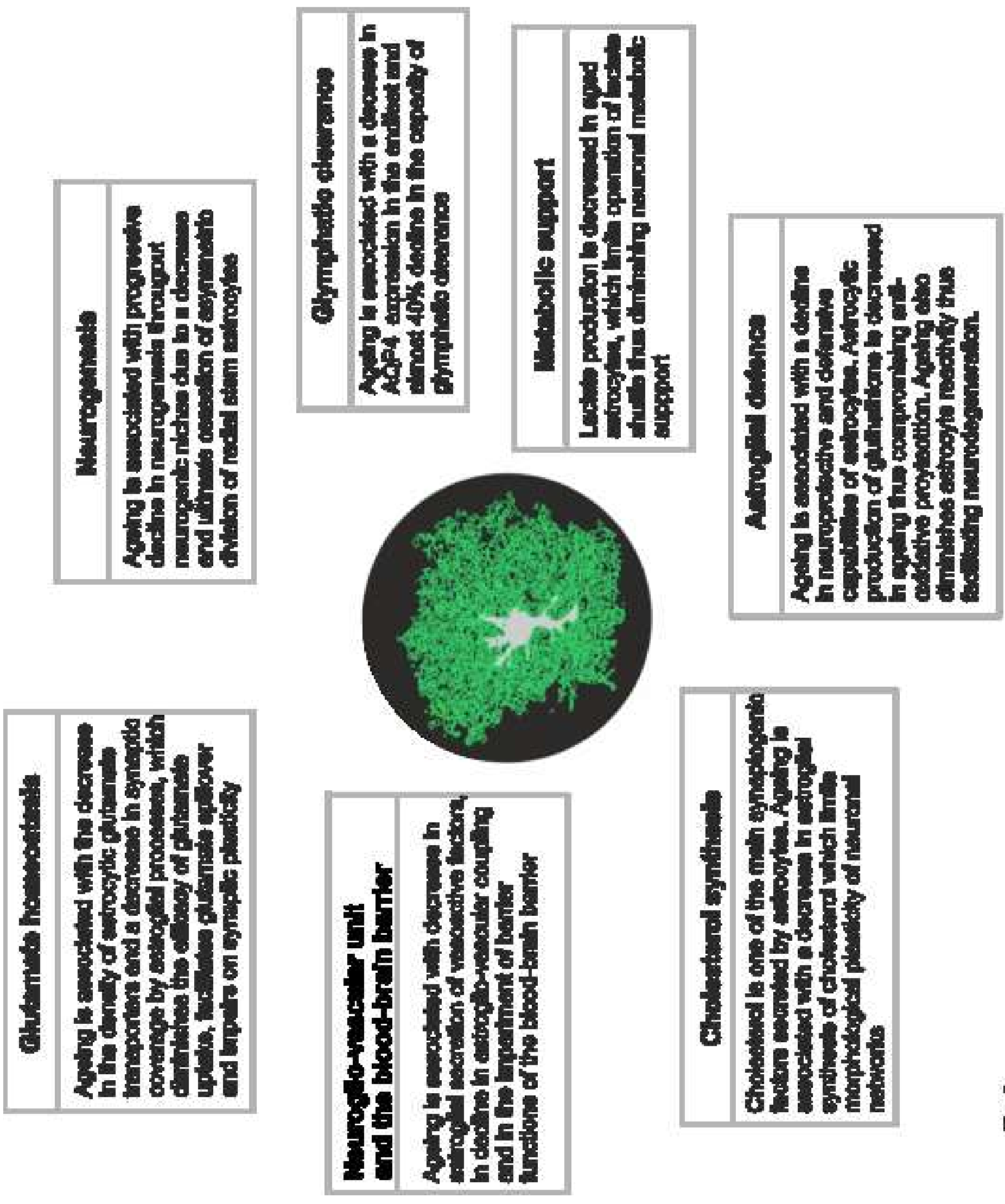

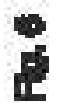

